\title{
Not in my neighbour's back yard? Laneway homes and neighbours' property values
}

\author{
Thomas Davidoff ${ }^{A}$ Andrey Pavlov ${ }^{\mathrm{B}}$ Tsur Somerville ${ }^{\mathrm{A}}$ \\ 7 September 2021 \\ ${ }^{\text {A }}$ University of British Columbia \\ B Simon Fraser University
}

\begin{abstract}
Single-family zoning is often defended as necessary to preserve neighbourhood amenities, but it is also blamed for making housing less affordable by constraining supply. In 2009, the City of Vancouver rezoned $95 \%$ of single-family areas to allow small accessory dwelling units (ADUs) or "laneway homes" behind residential structures. The goal was to increase rental housing supply with minimal disruption to rezoned neighbourhoods. We exploit this regulatory change to estimate the magnitude of externalities onto to nearby units from increases in density. We find that even this "gentle" densification negatively affects neighbouring properties. This negative spillover is strongest for higher-valued properties and non-existent for median and lower-valued homes. Our findings illustrate that the costs and benefits of added density depend importantly on neighbourhood type.
\end{abstract}

Key words: Externalities (D62), Housing Demand (R21), Housing Supply and Markets (R31), Land Use Regulations (R52),

1 We gratefully acknowledge BC Assessment's assistance in providing transaction and property characteristics data for this paper and a SSHRC grant for funding. We have also benefited from the comments of seminar participants at the Chinese University of Hong Kong, the Minneapolis Fed, National University of Singapore, Tel Aviv University, UBC, the University of Toronto, and the University of Washington and discussants at the AREUEA, AsRES, and UEA conferences. We especially thank the anonymous referees and the journal editor for their valuable comments and suggestions. 


\section{Introduction}

Rising housing costs have drawn attention to local restrictions on housing supply as a barrier to housing affordability. A large literature considers the connection between land use regulations, particularly strict local zoning policies that limit housing density in existing neighbourhoods, and home prices. ${ }^{2}$ It is widely believed that local opposition to new density and support for these restrictions comes from homeowners interested in preserving the character of their neighbourhoods and protecting the value of their own homes. ${ }^{3}$ This paper addresses a question central to the political economy of this opposition: to what extent do increases in local housing density negatively affect the value of existing homes? ${ }^{4}$

We test the effects of increased density from neighbouring properties on the sales prices of single-family houses using a change in zoning in Vancouver, Canada. ${ }^{5}$ In July 2009, the City of Vancouver changed its zoning by-laws to allow property owners in 95 percent of single-family zones to build a separate accessory dwelling unit ("ADUs") behind the main house. ${ }^{6}$ The ADU policy was introduced city-

$\overline{2}$ Among the many papers linking regulations to higher house prices are: ?, ?, ?, ?, ?, ?, ?, and ?.

3 See Dougherty, Connor. Golden gates: fighting for housing in America. New York: Penguin Press, 2020 for a discussion of opposition to new housing by existing residents, ? and ? for examples in the economics literature and ? for a review of the planning literature on this topic.

4 More broadly, models of city size and structure commonly include negative externalities of residential density as congestion that limits the aggregate positive effect of density enhancing agglomeration externalities (?, ?, and ?). Housing market research such as ? have focused not on density externalities but on the aggregate welfare gains from increased housing supply.

5 The City of Vancouver is the central city (2016 population 631,486$)$ of the $23 \mathrm{mu}-$ nicipalities in the Vancouver Census Metropolitan Area (CMA), Canada's third largest CMA (2016 population of 2,463,431). Among major US and Canadian cities (not metro areas) its population density of 14,226 persons per sq. mi. was third highest to New York City (27,016 persons per sq. mi. in 2010) and the City of San Francisco (a 2010 density of 18,679 persons per sq. mi.).

6 Vancouver was a relatively early adopter of ADU reform. Since 2010, regulatory changes in cities such as Portland, OR; Seattle, WA; and Toronto, ON; and Washing- 
wide, allowing a separate infill unit behind the main house, adjacent to the rear alley ("lane" in Vancouver, hence "laneway" home). The objective of the policy was to increase the supply and variety of rental housing without substantially altering the character of existing single-family neighbourhoods.

ADUs represent a type of "gentle densification" or "missing middle" housing that has been put forward as a built form between the extremes of low-density single-family detached units and high-rise apartments. It increases housing supply through higher density, but without substantial changes to a neighbourhood's built form, suggesting less obvious external spillover disamenity effects on neighbouring properties. Vancouver is an attractive location to study the effects of ADU density on neighbouring properties. This zoning change applied to almost all single-family zones, so we can study the impacts of infill construction without the concern that the newly allowed infill only occurs in particular rezoned neighbourhoods that may differ from other areas that were not treated by the the rezoning. Laneway adoption in Vancouver has been substantial: our own informal survey indicates that at the time of our data in 2017, the 2,913 laneway units in Vancouver were more ADUs than in any other city in North America to that point. Laneway homes have a similar footprint to garages and are located behind the main structure, so the policy did not change the street facing built form of neighbourhoods. Finally, while the units had to be rented, they do not have a separate title, laneway units are subject to high design standards, so that tenants are unlikely to be lower income households.

In the aggregate, allowing greater density may raise or lower local house prices. ?

$\overline{\text { ton, DC }}$, have encouraged or legalized ADUs and in 2017, California effectively legalized them statewide - see Kirk, M. Jan 16, 2018 https://www.citylab.com/design/2018/01/ the-granny-flats-are-coming/550388/. The remaining single-family zones received the ADU development option in 2013. After our study period, Vancouver allowed the construction of duplex homes on single-family lots, but without any increase in the allowable floor space ratio. 
and $?$ decompose the effect of changes in allowable built density into three distinct effects: own-lot, external, and supply effects. The own-lot effect is the beneficial redevelopment option owners obtain from increases in the allowed development density on their own lots. The external effect comes from negative spillovers from density onto nearby properties. The third effect is the downward pressure on house prices of increased supply. ${ }^{7}$ Our analysis is a test of the second effect. All property owners in the data receive the same own-lot redevelopment option (first effect). They also receive the same increase in housing supply (third effect), and moreover, this supply increase is limited to small one- to two-bedroom rental units that are poor substitutes for larger single-family residences.

We conceptually disaggregate externalities from residential density, the second or external effect, on nearby existing residents into three categories. First, additional residents may congest non-excludable public facilities such as on-street parking and schools. ${ }^{8}$ Second, existing residents may have a distaste for renters in general or for new residents who differ along some dimension from themselves, where racism would be the extreme form. Third, new density may be built in a way that reduces a resident's enjoyment of their private space, such as when a taller building casts shadows, blocks views, or compromises neighbouring homes' privacy.

Our study subject and identification strategy addresses both the first and third channels: congestion and the diminution of neighbouring residents' utility of their private space. The effect is clearest for the third effect as the occupants of laneway homes face directly into their neighbour's rear yard, an area that households more typically may see as unique private space. By contrast, the aggregate congestion effects are likely to be small as through 2017 the increase in neighbourhood density

7 Municipal-level fiscal and public goods effects of allowing new density, identified by ? and many others, are not salient in this study because we explore variation within a single municipality.

8 This effect could be positive if it enables entrepreneurs to overcome fixed costs and enter markets with retail amenities. 
and population from ADUs is small. A single laneway is just one additional one to two bedroom unit. Moreover, in 2017 the mean transaction in our data has 43 single-family units within $100 \mathrm{~m}$ but only 1.8 laneway units, reflecting a small overall increase in mean density. Finally, one of our tests below suggests that it is the loss of privacy effect that drives our observed negative spillovers.

We estimate the density externality of laneways on neighbouring single-family properties at different levels of granularity. The first class of estimates is of the effect on a property's transaction price of the number of laneway units within $100 \mathrm{~m}$. The second, narrower set of tests estimates the effect of an immediate neighbour's laneway using only newly built neighbours, comparing when the new-build has a laneway to when it does not. Using new homes lessens the estimation challenge of controlling for unobservable house characteristics that might be correlated with an existing owner's decision to build a laneway. New homes tend to be built to the maximum allowed density, and by policy design, adding a laneway home does not change the allowed, or observed, size of the main unit. Thus both depreciation and size are held almost constant conditional on location, lot size, and year built.

For all properties, the estimated mean spillover effect is negative in all our tests, but is not always statistically different from zero. In our cleanest identification, having a newly built neighbouring house with an ADU as compared to a newly built neighbour without an ADU, results in a $3.8 \%$ lower transaction price, though with a relatively small sample and many control variables, this effect is not statistically different than zero.

We find across specifications that the negative spillover effect increases in magnitude with predicted subject property price. The effects are close to zero and statistically not different from zero for lower-priced homes. The estimated negative spillover is consistently larger and statistically different from zero for properties above the 75 th percentile in predicted price. The estimated negative spillover on 
houses over the median predicted hedonic price is $5.7 \%$ and statistically different from zero, versus the overall $3.8 \%$ and insignificant effect. The variation we find in external effects matches a similar effect of adding laneways to one's own home: the impact of own laneway home on sale prices of new houses is more positive in neighbourhoods with lower average sale prices. Laneways are also more commonly built in less expensive neighbourhoods.

The heterogeneous response to spillovers by house price suggests differences in acceptance by wealth and income. A natural conjecture is that better-off households in more expensive housing have some combination of a lower marginal value of the additional income flow from a laneway in-fill, a larger distaste for the loss of privacy from sharing their backyard with another household, greater aversion to renters or added neighbourhood congestion, and a greater opportunity cost to losing some garage space that is a result of adding a laneway. ? also observe differential externalities to low income house developments by neighbourhood income. Unlike their subject, laneway residents are not poorer, subsidized households, but those able to pay market rent for new, high-quality detached rental units.

A challenge for empirical estimation of density externalities is the potential nonrandom placement of density. This results when density is endogenous to prices or correlated with unobserved variables that also effect local house prices. ? and ? find that zoning adjusts to market conditions, so higher density occurs in areas with high land prices. Our identification strategy rests on the claim that an owner or builder's choice to add a laneway home to a new structure is uncorrelated with unobservable property value characteristics within observable neighbourhoods. We test this identifying assumption in several ways all of which lend support to the argument of random placement within neighbourhoods particularly of new construction with laneway units. We are thus able to study realized changes in actual neighbourhood density rather than variation in the regulatory regimes of 
nearby municipalities, as in ?, or from the effects of non-randomly placed density as in much of the existing literature. ${ }^{9}$

In the next section we describe Vancouver's laneway policy. Section ?? details our data sources and identification strategy. We present our empirical findings in Section ??. Finally, in Section ?? we provide a discussion of the welfare implications of the City's laneway policy using our findings.

\section{Laneway Policy and Take-Up}

\subsection{Laneway Policy}

The City of Vancouver introduced its laneway policy in July 2009 aiming to further "Council priorities on affordable housing and sustainability" with a focus on rental housing supply. Both affordability and sustainability were understood to be achieved in part through increased density. The City saw laneway housing as contributing "to the rental housing mix and housing choice by providing small rental units in established neighbourhoods" with "little or no visible change in existing neighbourhoods." 10 The July, 2009 action provided a blanket allowance for laneway homes in all RS1 and RS5 single-family zones (95\% of single-family zoned properties). The remaining single-family and a small number of non-singlefamily zones were added in July, 2013. ${ }^{11}$

$\overline{9}$ ? and ? found that multi-family properties lower the values of the nearby single-family units. Others such as ?, ?, ?, and ? do not find that proximity, as measured by a sample of single-family properties a given distance from the location of the density under study, has an effect on their prices. None of these earlier studies address why density occurs in specific locations

${ }^{10}$ All quotes from June 9, 2009, City of Vancouver Policy Report, Urban Structure \#08-2000-20, https://council.vancouver.ca/20090721/documents/phea6.PDF.

${ }^{11}$ Not all single-family lots can accommodate a laneway. Lots need a lane backing on the site, sufficient width and depth, and adequate spacing between the laneway and the main structure (details in the Appendix). These restrictions affect approximately $16 \%$ of single-family zoned lots. 
Laneway units only modestly change building massing in detached single-family neighbourhoods because they roughly substitute for two-car garages. ${ }^{12}$ A laneway does not limit the allowed size of the main structure, though it can affect its positioning on the lot because of the required minimum distance between the main unit and the laneway. The opportunity costs of a laneway unit are mainly in the loss of garage space: for the typical 33 foot wide lot, a laneway unit design limits the property to up to a single car garage slot and/or a carport space. Wider lots can accommodate a two car garage slot as part of the laneway design. Despite the modest increase in density, the policy triggered opposition, with complaints including objections to density and congestion and to loss of parking and privacy. ${ }^{13}$

To address neighbourhood concerns about quality, the City implemented strict rules on laneway design, spacing and layout. Laneway homes are thus expensive to build and to rent. Construction costs for the median size unit are roughly $\$ \mathrm{C}$ 350 (\$US 260) per square foot, which is at the high end of single-family construction costs. ${ }^{14}$ The marginal cost of a laneway is lowest when constructed along with a new structure because approximately $\$ \mathrm{C} 50,000$ in laneway fixed costs for

\footnotetext{
12 A laneway footprint is smaller than that of a two-car garage, but at one and a half stories they are taller. Laneway homes are either one- or two-bedroom units, with a median size of $663 \mathrm{sq}$. ft. (61.6 sq. m.), with the range from the 10th to 90 th percentile of 489 to 865 sq. ft. ( 45.4 to 80.4 sq. m.), compared to 2,275 sq. ft. (211 sq. m.) for the mean new single-family structure.

${ }^{13}$ See https://www.theglobeandmail.com/news/british-columbia/ bcs-big-boom-in-little-houses/article1241009/ and https://bc.ctvnews.ca/ neighbours-unhappy-with-vancouver-lanewayhouses-1.565751. This is consistent with opposition observed elsewhere to modest increases in density: Gee, M., Globe and Mail, Aug 18, 2018 https://www.theglobeandmail.com/ news/toronto/toronto-has-lots-of-houses-and-towers-but-not-enough-inbetween/ article36030909/, https://www.planning.nsw.gov.au/policy-and-legislation/housing/ medium-density-housing/, Dougherty, C. New York Times, Dec. 1, 2017 https://www.nytimes.com/2017/12/01/business/economy/single-family-home.html provides a detailed example of just this type of opposition.

${ }^{14}$ All costs reflect 2017 conditions and prices: https://www.antaresproperties. com/how-much-cost-to-build-house/, ? and https://thethunderbird.ca/2010/04/08/ costs-piling-up-for-lanewayhouses-in-vancouver/.
} 
planning, permitting, landscaping, and engineering costs are already necessary for the main build. ${ }^{15}$ Additionally, the marginal cost of a laneway is only that part above the cost of building a two car garage that would be part of a new-build without a laneway.

Between the citywide rezoning to allow for infills in July 2009 and the end of 2017, 2,913 laneway units were built in the City of Vancouver. This represents $3.9 \%$ of the total single-family stock of 74,835 single-family detached structures, of which 66,893 were in areas zoned for the laneway infill units. Laneway homes were roughly $8 \%$ of housing units built in the City of Vancouver over this period and roughly $2 \%$ of units built in the larger CMA, or $32 \%$ and $13 \%$ respectively of the total number of purpose built rental units completed during this period.

In Figure ?? we show the distribution of these laneway infill units. We differentiate between those built as part of the construction of a new house (built 2010 or later) and those added to existing structures. Over two-thirds of laneway homes were built as part of a new construction, which in all cases required the teardown of an older, existing single-family unit. In total, for zones that allowed laneway homes, $31 \%$ of new single-family properties (built after 2009) had a laneway, while 1.5\% of those built prior to 2010 (existing homes) added a laneway. For units built after 2013, the laneway share among new-builds is over $40 \%$. While both types are distributed throughout the city, the concentration is higher is on the east side of the city, where $72 \%$ of laneway homes were built. The east-west density of laneway homes correlates broadly with price dispersion in the city: the May 2014 estimated price of a benchmark property in the city's more affluent western half was $\$ 2.2$ million was twice the $\$ 900,000$ for the same benchmark unit in the eastern half (referred to locally as the West and East Sides). ${ }^{16}$

\footnotetext{
$\overline{15}$ Based on conversations with laneway home builders and ?

16 May, 2014, Real Estate Board of Greater Vancouver statistics package, https://www. rebgv.org/market-watch.html.
} 


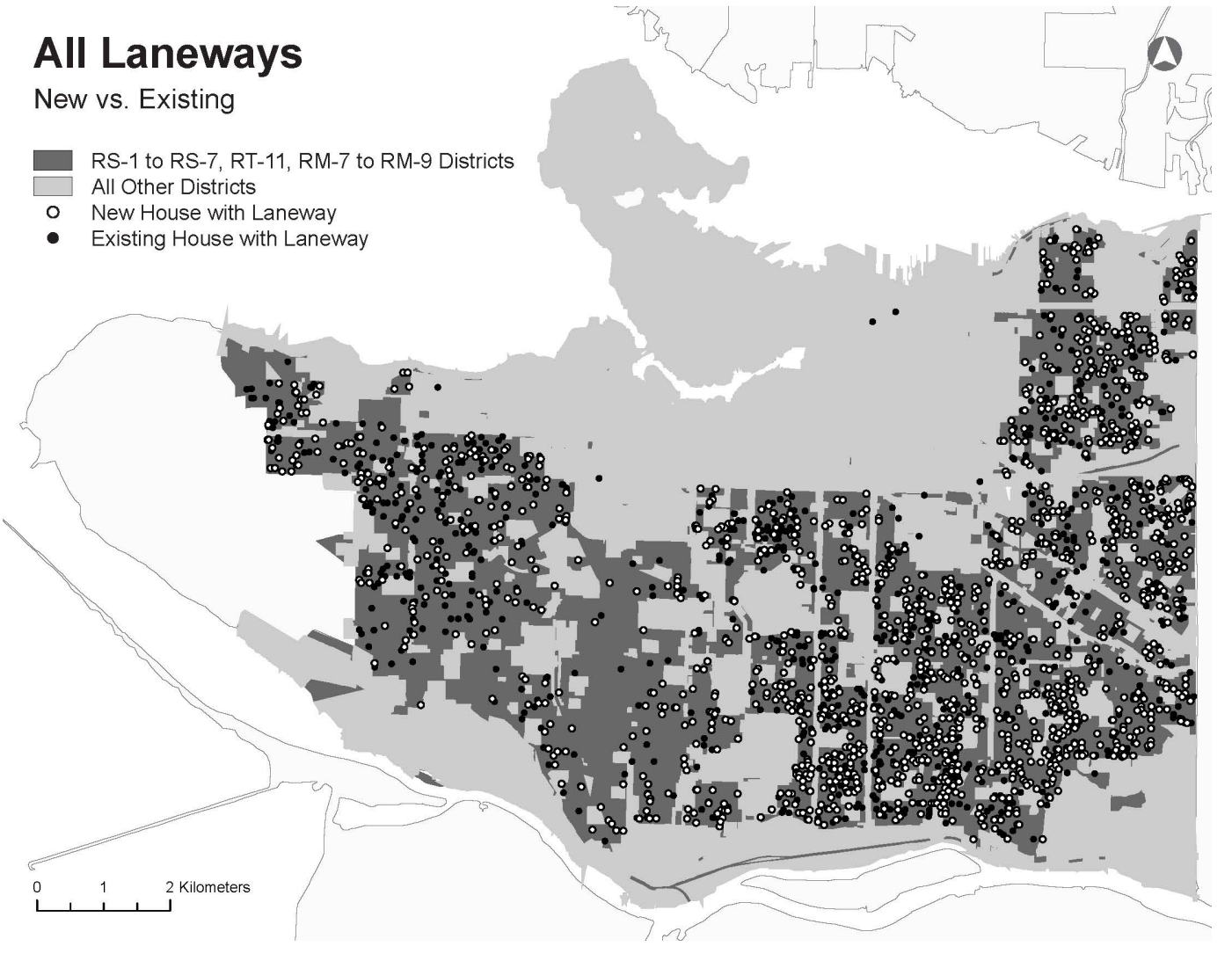

Fig. 1. Location of all laneway homes.

\subsection{Data}

Our data is the universe of properties in the City of Vancouver and all transactions of single-family properties from 2005 through 2017. These data come from BC Assessment, the Province's property assessment authority. The principal regressions and descriptive statistics use transactions from 2012-2017. Transactions from 2005-2008 are used in robustness tests. We combine the transaction data from Vancouver for single-family houses with property roll data that provides a rich set of property characteristics for all properties, allowing us to identify the characteristics of neighbouring properties, even if they do not transact. The full sample is winsorized at the 0.5 th and 99.5th percentiles on price, floor area, and lot size. We limit our transactions to those in areas with single-family zoning in 
2017 and where each included transacting property has a single-family unit adjacent on either side. We use transactions from 20 of the city's 30 neighbourhoods that had lots zoned for single-family detached units that permitted a laneway infill. ${ }^{17}$ This gives us a reduced sample of 20,930 transactions of single-family units from a full sample of 31,534 single-family transactions from 2012-2017. As explained above, laneway homes are more common with new-builds than existing units: $20.6 \%$ versus $1.6 \%$ among transactions. The geographic distribution of transactions by vintage with and without laneway homes is shown in Appendix Figures ?? and ?? and are visually similar to Figure ??.

It is challenging to identify the own or external property value effects of laneway homes built behind existing units. Builders claim that property owners who add a laneway to an existing unit do so with the intention to provide the unit to a family member or to create the option for themselves to downsize without leaving a neighbourhood as they age. However, in a city survey $85 \%$ of responding laneway occupants said they rent from a landlord as opposed to friends or family (?). Both suggest a long intended tenure, which might be correlated with unusual unobserved investment in the property or neighbourhood quality. By contrast, to be in our data, units must transact soon after laneway construction. We are concerned that transactions of older homes with laneways have unusual unobserved property or transaction characteristics.

Table ?? presents summary statistics for the total sample of single-family transactions and select subsets. For both new and existing units we provide separate summaries for both all units and those with laneway homes. An observation is

$\overline{17}$ Of the ten excluded neighbourhoods, five are in the high density downtown core, where the single-family units are heritage outliers. Another two have large numbers of singlefamily units, but were zoned for other types of residential uses such as duplex, triples, quadplex, townhouses, or have unique heritage zoning, and three have few single-family units. The remaining three have so few single-family properties with laneway units as to not offer identification given our neighbourhood-year controls. 
a transaction occurring over the period 2012-2017. Newer properties have larger floor areas, higher mean prices, and are more likely to be on the more expensive West Side, where both mean lot size and floor area are larger than on the East Side. Mean lot size is the same across both new and existing properties. New properties with laneway homes have lower average mean prices by $28 \%$, smaller floor area by $7 \%$, and smaller lot area by $10 \%$ than for all new units. This difference in part reflects laneway homes' higher incidence on the lower value East Side. Existing units with a laneway are slightly newer than existing structures without, but otherwise similar in observable property characteristics. Existing units with laneway homes are disproportionately on the East Side, though less so than for new homes. 


\begin{tabular}{|c|c|c|c|c|c|c|c|}
\hline \multirow[b]{3}{*}{ Variable } & \multirow{3}{*}{ mean } & & & \multicolumn{4}{|c|}{ Mean } \\
\hline & & \multirow{2}{*}{\multicolumn{2}{|c|}{ All homes }} & \multicolumn{2}{|c|}{ New homes } & \multicolumn{2}{|c|}{ Existing homes } \\
\hline & & & & All & Has Laneway & All & Has Laneway \\
\hline \multirow[t]{2}{*}{ Age } & 29.84 & 20.3 & 20930 & 1.79 & 1.24 & 34.89 & 30.37 \\
\hline & & & & $(-196)$ & $(-189)$ & $(26)$ & $(0.51)$ \\
\hline \multirow[t]{2}{*}{ Floor area $(000 \mathrm{sq} f t)$} & 1.69 & 0.71 & 20930 & 2.17 & 2.03 & 1.61 & 1.58 \\
\hline & & & & $(44)$ & $(21)$ & $(-11)$ & $(-3.14)$ \\
\hline \multirow[t]{2}{*}{ Has laneway home } & 0.04 & 0.21 & 20930 & 0.21 & 1 & 0.02 & 1 \\
\hline & & & & $(24)$ & $(661)$ & $(-12)$ & $(661)$ \\
\hline \multirow[t]{2}{*}{ No. laneway homes within $100 \mathrm{~m}$. } & 1.03 & 1.31 & 20920 & 0.96 & 1.57 & 1.04 & 1.26 \\
\hline & & & & $(-3.01)$ & $(9.06)$ & $(0.75)$ & $(2.73)$ \\
\hline \multirow[t]{2}{*}{ Lot size (000 sq ft) } & 5 & 1.79 & 20930 & 5 & 4.5 & 5 & 4.98 \\
\hline & & & & $(0)$ & $(-11.58)$ & $(0)$ & $(-0.27)$ \\
\hline \multirow[t]{2}{*}{ Price $(\$ 000)$} & 1766 & 1215 & 20930 & 2447 & 1794 & 1643 & 1490 \\
\hline & & & & $(24.85)$ & $(0.67)$ & $(-10.33)$ & $(-4.95)$ \\
\hline \multirow[t]{2}{*}{ No. residential units within $100 \mathrm{~m}$. } & 45.97 & 17.46 & 20920 & 46 & 49.2 & 45.96 & 45.93 \\
\hline & & & & $(0.09)$ & $(4.12)$ & $(-0.06)$ & $(-0.03)$ \\
\hline \multirow[t]{2}{*}{ No. single-family within $100 \mathrm{~m}$. } & 41.83 & 11.36 & 20920 & 42.23 & 44.46 & 41.76 & 41.57 \\
\hline & & & & $(1.89)$ & $(6.47)$ & $(-0.6)$ & $(-0.42)$ \\
\hline \multirow[t]{2}{*}{ West side } & 0.32 & 0.47 & 20930 & 0.46 & 0.2 & 0.29 & 0.23 \\
\hline & & & & $(14.85)$ & $(-7.53)$ & $(-6.4)$ & $(-3.56)$ \\
\hline
\end{tabular}

Table 1

Summary statistics by type of single-family home. $t$ statistics for type differences from all homes in parentheses 
In the regressions we present specifications where we limit consideration to transacting properties that have a newly built adjacent property (defined as less than five years old). The newly built neighbours all represent tear-downs of existing homes. In this case, identification comes from whether the newly built neighbour has a laneway or not. The sample size when we limit transactions to those with a newly built neighbour falls to 2,244 transactions. Of these, 535 have a new-build neighbour with a laneway and 1,709 have a new-build neighbour without. Descriptive statistics for this sample are presented in Appendix Table ?? In general, the transacting units with an adjacent newly built neighbouring house with a laneway are less expensive, smaller, and on smaller lots, than transacting properties with a newly built adjacent single-family house without a laneway. Much of this difference in mean lot and property size reflects the east-west split in price and laneway incidence in the city noted earlier.

\subsection{Random Laneway Placement}

A key assumption of our regression analysis is that conditional on controls, the location of laneway homes is random. In particular, we assume zero correlation between laneway home placement and unobserved hedonic features of either own or neighbouring properties. The stark differences in laneway incidence and mean transaction price between Vancouver's East and West Sides highlight the need to test the validity of this assumption. We present three tests of the validity of our assumption of random assignment of laneway homes conditional on our mean neighbourhood effects and other controls. First, whether more detailed geographic controls are likely to be a source of unexplained house price variation. Second, whether houses where newly built neighbouring units have laneway homes are systematically different from single-family properties where the newly built neighbouring units did not include a laneway home. Third, whether new houses with laneway homes are built in neighbourhoods that differ in observable ways 
from areas where new houses are built without laneway homes.

The first test for random assignment asks whether house prices are more homogeneous in sub-neighbourhood areas than in the broader neighbourhoods for which we can include dummy variables. For transaction count reasons, we measure neighbourhoods as defined by BC Assessment, but data are available at lower levels of aggregation. One way to determine whether our neighbourhood-year controls are adequate to capture geographic variation in location quality that might be associated with laneway placement is to ask if sub-neighbourhood geographies explain within-year variation in prices. If sub-neighbourhoods provide information on property value within neighbourhoods, then the possible concentration of laneway homes within neighbourhoods into high- or low-value sub-neighbourhood geographies would be a significant concern. We find that at the city level, the standard deviation of log transaction prices purged of year means is .690. Controlling for the East/West divide, we find that the standard deviation of log price purged by year-East/West mean is .530. Purging neighbourhood-year means leaves a standard deviation of .504, and purging Census Tract-year means leaves a standard deviation of .502. This suggests that laneway homes are unlikely to be placed in better or worse census tracts within neighbourhoods, as there is very little variation across tracts within neighbourhoods.

The second and third checks for random placement are discussed in more detail and tabulated in Section ??. These compare transaction prices pre-laneway (200508) with outcomes and prices post-laneway (2012-17). Briefly, we find that preperiod prices of transacting properties that will have a new-build neighbour with a laneway in the post-period are than those whose post-period new-build neighbours do not have a laneway. Aggregating to the census tract level, we do not find that pre-2010 prices were systematically higher or lower in tracts with higher than neighbourhood-average shares of laneway homes. These tests generally do not 
suggest a bias towards finding adverse price impacts of neighbouring laneway homes due to micro-neighbourhood unobservables.

\section{Estimation and Identification}

\subsection{Social Welfare Context}

Our empirical analysis emphasizes the external effect of laneway home construction, particularly the impact of a laneway added to a new home among neighbouring owners. These external effects form part of the welfare effects of allowing laneway homes. More broadly, the introduction of laneway homes affects welfare in both the rental housing and single-family owner-occupied markets. Laneway homes are typically rented in an arms-length relationship, so their introduction approximately allowed a supply curve from owners of single-family detached properties to intersect a demand curve from renters. Prior to the policy, this laneway rental market was constrained to have zero supply.

In Section ??, supplemented by Appendix ??, we present a simple partial equilibrium welfare analysis of the laneway policy that includes a discussion of renters' consumer surplus. Homeowners who add laneway homes earn producer surplus equal to the difference between the present discounted value of market rent (or in some cases the value of space for family) for the laneway minus the (observable in principle) cost of replacing a garage with a laneway home and the (unobservable) utility costs of lost privacy and garage space plus the eventual resale effect of the laneway. This is the own-lot effect described above. ${ }^{18}$

\footnotetext{
$\overline{18}$ Laneway home theoretically could affect owner prices through a substitution effect. However, laneways cannot be purchased, owner and rental homes are imperfect substitutes, and laneway homes are much smaller than detached homes. We thus assume that household switching from owning a detached unit to renting a laneway is negligible and assume away that price impact.
} 


\subsection{Laneway Option Value}

The enabling by-law granted an option to owners of existing homes to add a laneway unit that should have had a positive own-lot effect on property values. The announcement may also have led homeowners to anticipate external effects of neighbouring laneway homes over time. Our estimates of the marginal impact of nearby laneway homes on own or neighbouring property values will not capture this net option value and expected external effect because all transacting properties in these regressions are laneway-eligible. Appendix ?? provides difference-indifferences estimates of the value of option endowment. Standard errors are large, and we can rule out neither large positive nor a wash between large or small own-lot effects and anticipated external effects. This is not surprising because the rezoning occurred in only two stages, with insufficient variation between rezoned and non-rezoned properties to allow for proper identification of the value of option endowment.

\subsection{Laneway Option Exercise Effects}

To estimate the impact of a laneway-home on the owner's property value we consider sales prices of homes that are sold after the 2009 option grant that are laneway eligible. Among these homes we use a dummy variable $L_{i t}$ to distinguish among those that sell with a laneway home and those that do not. We regress:

$$
p_{i, j, t}=\beta_{0}+X_{i, t} \beta_{1}+\beta_{2} L_{i, t}+\mu_{j, y}+\gamma_{t}+\epsilon_{i, t} .
$$

In (??) $p_{i, j, t}$ is the log transaction price $p$ for house $i$ in neighbourhood $j$ at time period (month-year) $t . X_{i, t}$ are characteristics of the property $i$ at time $t, L_{i, t}$

equals one if property $i$ has a laneway unit at the time of sale, $\mu_{j, y}$ is a dummy 
for the neighbourhood-year combination $j, y$, and $\gamma_{t}$ is the effect of sale in yearmonth $t$. The time measurement $y$ is annual but $t$ is monthly, as it is not feasible to estimate neighbourhood-month fixed effects. The coefficient of interest, $\beta_{2}$, measures the contribution of a laneway to own property value. Following standard practice in hedonic regression, we estimate these regressions with the dependent variable transaction price in logs and the right hand side variables in levels. In the discussion of results, we document consistency with results in levels.

\subsection{Effect on Adjacent Property}

Our approach to estimating the effect of a laneway home on neighbours is similar to that for own effects. The general external effect regression for properties that vary by proximity to the source of the externality (the laneway) is:

$$
p_{i, j, t}=\beta_{0}+X_{i, t} \beta_{1}+\beta_{2} L_{i, t}+\beta_{3} N L_{i, t}+\beta_{4} N P_{i, t}+\mu_{j, y}+\gamma_{t}+\epsilon_{i, t}
$$

Equation (??) is a generalization of (??) in that the right hand side variables in (??) are a subset of those in (??). The variable " $N L$ " measures the presence of nearby laneway homes. We define the treatment of "nearby" laneway homes $N L_{i, t}$ in different ways. First, as the count of laneway homes within different radii of transacting properties. Second, we use a dummy if there is a single-family property with a laneway immediately adjacent to the transacting property. As laneway homes more often come along with a new house than not, it is prudent to count nearby new homes, denoted $N P_{i, t}$ in the estimating regression (??).

How the coefficient $\beta_{3}$ on nearby laneway varies with the definition of "nearby" may inform which of the three forms of local density externalities described in the 
introduction may be most active. Specifically when the coefficient $\beta_{3}$ is much larger when the treatment is highly localized, this would provide support for the idea that a large part of the externality we estimate is the loss of privacy and amenity inside neighbours' property. By contrast, if the treatment effect $\beta_{3}$ is relatively constant as the treated radius grows within a neighbourhood, that would suggest local congestion or composition effects are relatively important sources of any externalities.

Figure ?? above shows that at a citywide level, laneway homes are not randomly distributed in all single-family zones, but are concentrated more intensively in Vancouver's less expensive East Side. To absorb these coarse geographic differences, all regressions have on the right hand side the neighbourhood-year fixed effect $\mu_{j, y}$ for twenty neighbourhoods in the sample as defined by the province's property assessment authority. For unbiased estimation with these fixed effects, the allocation of laneway homes within neighbourhoods must be random, conditional on included unit characteristics and time covariates.

In the specifications we consider best-identified, we limit consideration to transacting properties that have an immediate neighbour that is newly-built main structure (within the past 5 years). All of these new homes represent tear-downs of existing homes. ${ }^{19}$ For this sample, $N L$ indicates that the new neighbouring home includes a laneway home. We prefer the newly built neighbour sample because the control group (newly built neighbours without laneway infills) is much more likely to be similar to the treatment group (newly built neighbours with laneway infills) than would be the treatment group of older houses in general versus those with an added laneway. ${ }^{20}$

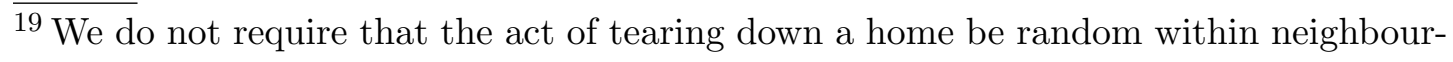
hoods in those specifications, rather that the choice to place a laneway home behind a new primary home or not is uncorrelated with features of the own or adjacent lot relative to other lots in the neighbourhood.

${ }^{20}$ For neighbouring units the mean floor space to lot area ratio for new homes is 0.44
} 


\section{Results}

\subsection{Impact of Own Laneway House}

Our first test is the estimation of equation (??) that considers the own property value impact of building a laneway house. These and all following regressions include (unreported in tables) the lot size, structure characteristics, and neighbourhood-year controls $\left(X_{i, t}, \mu_{j, y}\right.$, and $\left.\gamma_{t}\right)$ per equation (??). The results reported in Table?? splits the sample by new (built within 5 years prior to the transaction date) vs. old (existing) houses, and among new houses by location on the eastern or western sides of the city.

\begin{tabular}{|c|c|c|c|c|c|}
\hline & $(1)$ & $(2)$ & $(3)$ & $(4)$ & $(5)$ \\
\hline VARIABLES & Full Sample & New House & Old House & New: East & New: West \\
\hline \multirow[t]{2}{*}{ Property has a Laneway unit } & -0.026 & $0.114^{* * *}$ & -0.008 & $0.153^{* * *}$ & 0.054 \\
\hline & $(0.019)$ & $(0.036)$ & $(0.035)$ & $(0.043)$ & $(0.080)$ \\
\hline \multirow[t]{2}{*}{ Dummy, $=1$ if laneway suitable } & 0.003 & 0.028 & -0.002 & $0.066^{* *}$ & 0.040 \\
\hline & $(0.010)$ & $(0.021)$ & $(0.011)$ & $(0.033)$ & $(0.029)$ \\
\hline Observations & 21,175 & 3,204 & 17,971 & 1,319 & 1,885 \\
\hline R-squared & 0.707 & 0.819 & 0.676 & 0.608 & 0.684 \\
\hline neighbourhood/time effects + controls & Yes & Yes & Yes & Yes & Yes \\
\hline
\end{tabular}

Robust standard errors in parentheses

$* * * \mathrm{p}<0.01, * * \mathrm{p}<0.05, * \mathrm{p}<0.1$

Table 2

Effect of own laneway home. The table reports the impact of having a laneway unit as estimated by Equation (??). We report the estimates for a new house (five years or less of age) and an existing house (over five years old). We further break the sample down by East/West halves of the city and by price. The positive effect of laneway houses on price is statistically different from zero only for lower-priced properties and for new properties on the east side. All regressions have controls for both neighbourhood-year and city wide year-month fixed effects

In Table ??, among all homes, specification (1) shows that the addition of a laneway is associated with a statistically insignificantly lower sale price of roughly $2.6 \%$. Among new homes, a laneway house is associated with higher property value of roughly $11.4 \%$, per specification (2). At the sample mean this is $\$ \mathrm{C} 259,300$,

with a standard deviation of 0.054 , while for existing homes the mean is 0.33 with a standard deviation of .103. 
which is within the plausible range of cost including mark-up to build a laneway home instead of a two car garage. Adding a laneway to an existing house does not appear to increase its resale value, as the coefficient of interest in specification (3) is $-.0 .7 \%$, statistically indistinguishable from zero. However, as we note above, existing homes where property owners add a laneway and then sell the property seem to be more likely to have unobserved property or transaction characteristics complicating the interpretation of this coefficient. ${ }^{21}$

The results in specifications (4) and (5) of Table ?? are consistent with the difference in laneway uptake between Vancouver's East and West Sides. The figures and summary tables above show a notably higher incidence of laneway uptake on the lower priced East Side. In regressions (4) and (5) of Table ??, the marginal percentage contribution of a laneway to property transaction price is three times as large for new East Side properties as new West Side. Adjusting for the higher West Side prices, the dollar amount is still 50\% larger on the East Side.

Arbitrage considerations suggest that in neighbourhoods where builders commonly build new homes both with and without a laneway, adding a laneway to a new home should add roughly as much resale value as the typical incremental all-inclusive cost of construction. ${ }^{22}$ There is room for market value added to be less than cost among existing homes and "custom" new homes, where incumbent owners may have idiosyncratic preferences for laneway homes versus privacy and larger garages that differ from the market valuation (e.g. family needs, low discounting of future rents, or optimism about future value). The results in Table ??

\footnotetext{
$\overline{21}$ These sales, which applies to all older homes with laneway units in this sample, could signal difficult life cycle events clouding interpretation of the near-zero coefficient.

22 This statement assumes that markets are sufficiently thick that speculative builders have similar beliefs about the premium attached to a laneway when starting their projects. With heterogeneous costs to add laneways and heterogeneous demand for single-family properties with an added laneways, a mixed equilibrium could also arise with price below average incremental cost to build a laneway.
} 
are consistent with those considerations.

\subsection{Impact of Nearby laneway houses}

Our primary objective in this paper is to measure the spillover from density. Our first approach uses equation (??), where we add the number of laneway houses within a 100-meter ring around each observation to the specification used above in Table ??. ${ }^{23}$ We also include the number of new single-family properties within the same radius as a control for potential number of laneway homes, reflecting the substantially higher incidence of laneways among new homes compared to existing properties. We report our results in Table ??. This table shows results for the full sample, sub-samples for houses with higher predicted prices, and a set of locally-weighted least squares regressions where the weights are the inverse of the difference between an observation's predicted price and benchmark percentiles in the predicted price distribution (10th, 25th, 50th, 75th, or 90th). ${ }^{24}$

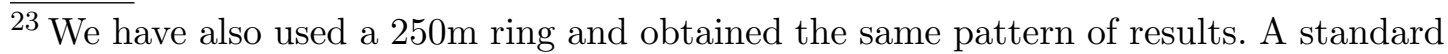
Vancouver block is $180 \mathrm{~m}$ long giving a $100 \mathrm{~m}$ radius a diameter of about a single block. 24 The predicted price, here and throughout the paper, includes the same covariates as the specification in Table ??. For the purpose of predicting the price for splitting the samples in this table, and in all subsequent tables, we use the actual physical characteristics and location of each property, but fix the time to a specific point (January $1,2015)$ to avoid categorizing properties by time of sale. 
All laneway homes and 1-family counts, 100-meter ring

\begin{tabular}{|c|c|c|c|c|c|c|c|c|}
\hline & $(1)$ & $(2)$ & $(3)$ & $(4)$ & $(5)$ & $(6)$ & $(7)$ & $(8)$ \\
\hline VARIABLES & Full sample & High pp & Very high pp & w10 & w25 & w50 & w75 & w90 \\
\hline \multirow[t]{2}{*}{ No of laneways within $100 \mathrm{~m}$, excl. own } & $-0.009 * *$ & $-0.016^{* * *}$ & $-0.025^{* * *}$ & -0.004 & 0.001 & -0.003 & $-0.006^{* *}$ & $-0.016^{* * *}$ \\
\hline & $(0.004)$ & $(0.006)$ & $(0.007)$ & $(0.003)$ & $(0.002)$ & $(0.002)$ & $(0.002)$ & $(0.004)$ \\
\hline \multirow[t]{2}{*}{ No of new 1-fam within $100 \mathrm{~m}$} & 0.004 & 0.006 & 0.003 & 0.002 & -0.001 & $0.003^{* *}$ & 0.002 & $0.004^{* *}$ \\
\hline & $(0.003)$ & $(0.004)$ & $(0.005)$ & $(0.002)$ & $(0.002)$ & $(0.001)$ & $(0.002)$ & $(0.002)$ \\
\hline \multirow[t]{2}{*}{ Property has a Laneway unit } & -0.024 & -0.057 & $-0.076^{* *}$ & -0.014 & 0.001 & $0.035^{* *}$ & $0.031^{* *}$ & 0.005 \\
\hline & $(0.019)$ & $(0.035)$ & $(0.035)$ & $(0.016)$ & $(0.013)$ & $(0.015)$ & $(0.015)$ & $(0.018)$ \\
\hline Observations & 21,175 & 9,954 & 4,597 & 21,175 & 21,175 & 21,175 & 21,175 & 21,175 \\
\hline R-squared & 0.707 & 0.567 & 0.465 & 0.537 & 0.489 & 0.591 & 0.763 & 0.833 \\
\hline neighbourhood/time effects + controls & Yes & Yes & Yes & Yes & Yes & Yes & Yes & Yes \\
\hline
\end{tabular}

*** $\mathrm{p}<0.01,{ }^{* *} \mathrm{p}<0.05,{ }^{*} \mathrm{p}<0.1$

Table 3

Effect of nearby laneway homes. This table reports the estimation of Equation (??) for all transactions using the laneway counts and single-family counts. "High pp" and "Very high pp" are based on sub-samples of properties whose predicted price is above the median and above the 75th percentile, respectively. The locally-weighted least squares regressions, (4) through (8), use weights that are inversely proportional to the absolute distance measured in predicted price to the listed percentile of the predicted property price distribution. The negative effects of both laneway homes and overall density are concentrated in the higher-valued properties. We detect no effect in the average or below average-priced properties. All regressions have controls for property and lot characteristics, neighbourhood-year fixed effects, and city wide year-month fixed effects. 
In Table ?? the number of laneway houses within a 100-meter radius is associated with a $0.9 \%$ lower price per laneway house, a statistically different from zero effect. The negative effect of nearby laneway houses on a given property's price is larger when we limit the sample to houses with higher predicted prices, $-1.6 \%$ for the sample above the median predicted price and $-2.5 \%$ for the 75 th percentile. ${ }^{25}$ Similarly using the locally-weighted least-squares regressions (specifications (4) through (8)) the externality is statistically indistinguishable from zero when regressions are weighted towards lower predicted price but increases in absolute value as the weighting moves towards those closest to a higher predicted price: from $-0.4 \%$ weighted to the 10 th percentile to $-1.6 \%$ weighted to the 90th percentile. Only the larger negative effects for weighing to the 75th and 90th percentiles of predicted price are statistically different from zero.Appendix Table ?? runs the same type of test, but uses unconditional quantile regressions for the 10th through 90th percentiles of the predicted price distribution. This specification yields results qualitatively similar to the locally weighted regressions above in Table ??: negative, with larger magnitude point estimates at higher quantiles.

The external effects of nearby laneway homes may be nonlinear. In Appendix Table ?? we use fixed effects for different numbers of laneway homes rather than the continuous measure used in Table ??. The reults indicate a declining marginal effect of additional laneway homes. ${ }^{26}$ In the full sample, one laneway home within $100 \mathrm{~m}$ is associated with a $2.8 \%$ lower price, the marginal effect declines with additional laneways nearby. As in the other tables, the impact of any quantity of

$\overline{25}$ Since counts of nearby homes in 100-meter rings and unobservable neighbourhood characteristics may be spatially correlated, the standard errors reported in Table ?? could be biased. However, we find that when we account for spatial autocorrelation using the methods developed by ?, there is no increase in our estimated standard errors. ${ }^{26}$ We even find that three laneway homes have a less negative price effect than two, but we cannot reject that any of the point estimates are different from each other. Estimating the effect of a third or fourth laneway is challenging due to sample size. $45.8 \%$ of transactions have no laneway home within $100 \mathrm{~m}, 27.6 \%$ have one, $14.5 \%$ have two, $6.5 \%$ have three, $3.0 \%$ have four, and $2.6 \%$ have more than four. 
neighbouring laneway homes is more negative for higher-value properties.

Table ?? estimates the relationship between log price of a home and the count of laneway homes (excluding the property's own laneway home) within different radii from the transacting property. The control variables are as above. Specification (1) shows that the relationship between a neighbouring home having a laneway home and a subject property's price is negative at 0-50, 50-100, and 100 to 250 meters, with the point estimates declining with distance. The separate effects of the count of laneway homes within the three outer bounds 50, 100, and 250 meters are reported separately in specifications (2) through (4); again, the estimated impact declines with distance. This attenuation with distance is consistent with external effects that include both broader effects like congestion, with negative effects across all radii, and highly localized effects like loss of privacy, where the largest effects are for the closest properties.

\subsection{Impact of a Newly Built Neighbouring Laneway House}

As a cleaner test of highly localized spillovers from density we limit the analysis to transacting homes for which one of the two immediate neighbours of the transacting property was newly built at the transaction date. We compare transaction prices of homes with adjacent new homes with laneways to prices of properties with adjacent newly built homes that do not have a laneway. ${ }^{27}$ Here, identification comes from the difference between the transaction price of a house that has a newly built neighbour that has a laneway home and the price of an observably similar house that has a newly built neighbour that does not have a laneway home. As noted above, the characteristics of new homes within a neighbourhood-year are less heterogeneous than is the case for existing homes.

$\overline{27}$ The sample is limited to transacting properties with an adjacent single-family unit on each side. If there is a laneway home, it is only with a newly built neighbouring house. We also exclude the transacting house if it has a laneway. We also exclude properties with two adjacent laneways. 


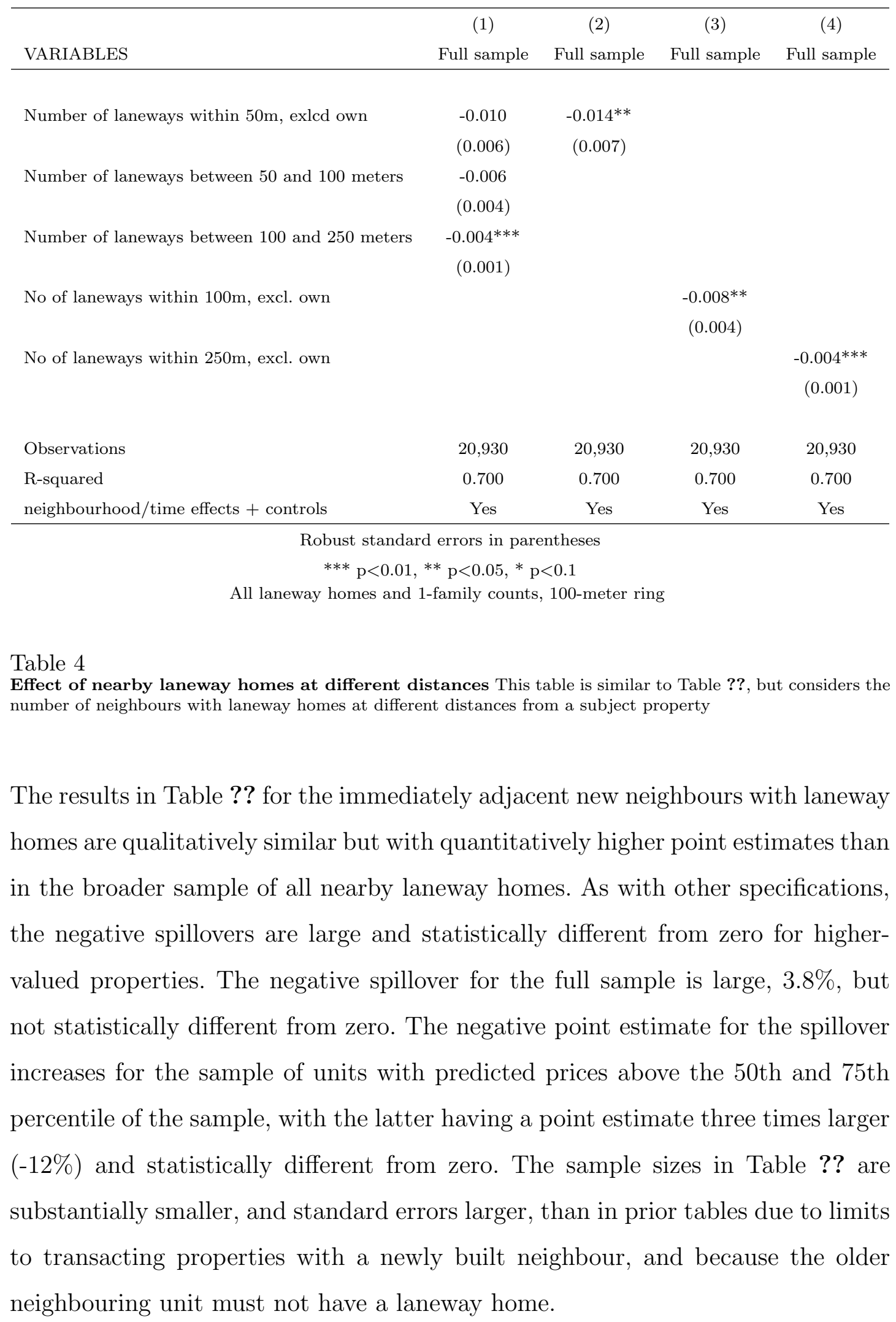


For the locally weighted regressions, as in previous regressions, the point estimates are not statistically different from zero for regressions that are weighted by the distance between the unit's predicted price and up to the mid-range of the predicted price distribution. The negative spillover is largest, at $7.2 \%$, and highly significant when observations are weighted by the distance between their predicted price and the 90th percentile.

Appendix Table ?? repeats the analysis of Table ??, but uses unconditional quantile regressions to estimate the impact of neighbouring laneway homes at different points in the distribution of home quality and value. Again, we find that impacts of laneway homes are more negative near the top of the home value distribution. Point estimates in this specification are generally more negative than those we find with weighted least squares, as in the case of all homes in Table ?? and Appendix Table ??. 
Single-family neighbourhoods, new neighbours only

\begin{tabular}{|c|c|c|c|c|c|c|c|c|}
\hline & (1) & $(2)$ & $(3)$ & $(4)$ & (5) & (6) & $(7)$ & (8) \\
\hline VARIABLES & Full sample & High pp & Very high pp & $\mathrm{w} 10$ & $\mathrm{w} 25$ & w50 & w75 & w90 \\
\hline \multirow[t]{2}{*}{ New neighbour has laneway } & -0.038 & $-0.057^{*}$ & $-0.120 * * *$ & -0.009 & -0.001 & -0.029 & -0.015 & $-0.072^{* * *}$ \\
\hline & $(0.026)$ & $(0.031)$ & $(0.043)$ & $(0.024)$ & $(0.016)$ & $(0.018)$ & $(0.018)$ & $(0.019)$ \\
\hline Observations & 1,312 & 850 & 472 & 1,312 & 1,312 & 1,312 & 1,312 & 1,312 \\
\hline R-squared & 0.789 & 0.708 & 0.610 & 0.773 & 0.681 & 0.677 & 0.778 & 0.849 \\
\hline neighbourhood/time effects + controls & Yes & Yes & Yes & Yes & Yes & Yes & Yes & Yes \\
\hline
\end{tabular}

Robust standard errors in parentheses

$* * * \mathrm{p}<0.01, * * \mathrm{p}<0.05, * \mathrm{p}<0.1$

Table 5

Effect of immediate neighbour's laneway home (new neighbours only). The table reports the estimation of Equation (??) for transactions where there is a newly built (past 5 years) neighbouring single-family property. "High pp" and "Very high pp" are based on sub-samples of properties whose predicted price is above the median and above the 75 th percentile, respectively. The locally-weighted least squares regressions, (4) through (8), use weights that are inversely proportional to the absolute distance measured in predicted price. Having a neighbour with a laneway house has a very marginal and insignificant effect for low and mediumpriced properties. However, it has a large and significant negative effect for higher-priced properties. All regressions have controls for property and lot characteristics, neighbourhood-year fixed effects, and city wide year-month fixed effects. 
Following convention, we have presented results in logs rather than levels. Because we are particularly interested to know whether high value homes see a larger penalty associated with an own or adjacent laneway, the levels specification has the result that a smaller log effect for more expensive homes could be associated with a larger levels effect. Appendix Table ?? shows our results of greatest interest in logs as presented above and from levels specifications.

Our laneway effect estimates include neighbourhood-by-year and general yearmonth fixed effects. If as in ?, adding own home characteristics and more specific neighbourhood controls reduces the magnitude of the estimated coefficient of interest, then additional unobservables could be expected to also do so as well, so that our results might well be biased from non-random laneway incidence. To evaluate this, we examine the effect of adding census tract fixed effects. Doing so drops all observations from 5 of the 72 census tracts that have no laneway homes and hence their laneway variable is co-linear with their neighbourhood fixed effect. Thus, we evaluate the effects of increased geographic granularity, but restrict to census tracts with above the median number of home transactions with new adjacent neighbouring homes with a laneway unit. In Appendix Table ?? as we move from no controls, to neighbourhood-time effects only, to adding the lot and structure control there are substantial changes in the estimated coefficient on neighbouring new-build with a laneway. However, these stop with the addition of census tract dummy variables: the coefficient on laneways moves from -.096 with neighbourhood effects to -.097 with tract dummies. This very small effect is also in the opposite direction from what would be expected if adverse unobservables were correlated with laneway placement. We thus gain some comfort that capturing further micro-neighbourhood characteristics would be unlikely to have much effect on our coefficient estimates.

Appendix Table ?? considers a broader definition of what is a neighbouring prop- 
erty, that includes the nearest neighbour behind and across a lane and in front across the street. The coefficient on adjacent laneway home alone is larger in magnitude than when they are pooled $(-3.8 \%$ versus $-2.2 \%)$, suggesting that the negative externalities are strongest for the adjacent neighbours as opposed to those behind and across the lane or in front and across the street. The implication of this difference is that for laneway homes, the density externality is more likely to be from the loss of privacy (private consumption) than congestion or neighbourhood change, as the privacy loss is effectively only from an adjacent property while the congestion and change effects should apply more similarly to effects from the other neighbouring units.

\subsection{Introduction of the First Nearby Laneway Home}

The tests presented above do not explicitly measure the effect of adding a laneway home to a neighbourhood where none were previously present. A difference in differences (DiD) specification would perform that test and do so in a way controlling for time invariant neighbourhood unobservables. ? offer a methodology for DiD with continuous treatment dates and geographically varying controls that might be suitable for the construction of laneway units in neighbourhoods. However, because we have roughly one-thousandth the number of observations as they do and only 7 transactions per laneway home in the full sample compared to their over 2,000 for each of their more geographically diffuse low income housing developments, we do not have the data to use their approach of distinct laneway home specific control groups. Formally, we cannot include treatment area fixed effects.

Instead we use an event style specification that can be thought of as a quasi-DiD estimation.

Our quasi-DiD approach compares a sub-neighbourhood after a laneway home has 
arrived to itself prior to the date the first laneway home is constructed in the area and to areas where no laneway homes are ever built. We use two definitions of sub-neighbourhood: either the postal code (full 6 character code) or just the first five characters of the code. These consist of 1-2 block faces or 1-2 full city blocks respectively. Unlike a conventional $\mathrm{DiD}$, to preserve degrees of freedom, we do not have fixed effects for these sub-areas, only for our broader neighbourhoods, which on average include 285 postal codes or 56 five digit postal codes. ${ }^{28}$ A transaction is deemed to be "treated" if it is located in a postal area in year $t$ or $t+n$ when the first laneway home was built in year $t-1$ and no other laneway homes are built in the area. ${ }^{29}$ The effect estimated is the difference in log price, relative to the broader neighbourhood-year mean between (a) homes in treated postal areas that transact in the year after the first laneway home is built versus (b) either: (i) in an untreated postal area (that never receives a laneway home), or (ii) in a treated postal area sold prior to the year the first laneway home is built.

In Table ?? we present the results of this quasi-DiD. The postal area groups are the postal code for regressions (1) and (2)) or larger first 5 characters of the postal code for regressions (3) and (4). For postal areas where the first (and only) laneway home was built in year $t-1$ regressions (1) and (3) include transactions in years $t+n$ yielding substantially larger sample sizes than regressions (2) and (4) that only consider year $t$ observations for the treated group.

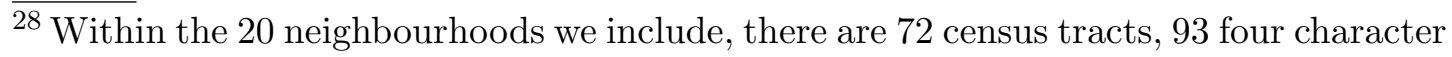
postal code groups, 1,113 five character postal code groups, and 5,743 postal codes.

${ }^{29}$ We exclude transactions in the year of he laneway home completion $t-1$ as we do not know when in the year the laneway home was begun or completed.
} 
Effect of newly constructed nearby laneway home

\begin{tabular}{|c|c|c|c|c|}
\hline \multirow[b]{2}{*}{ VARIABLES } & (1) & $(2)$ & (3) & \multirow{2}{*}{$\begin{array}{c}\text { (4) } \\
\text { 5-digit postal } \\
\text { laneway neigh only }\end{array}$} \\
\hline & 6 -digit postal & $\begin{array}{l}\text { 6-digit postal } \\
\text { laneway neigh only }\end{array}$ & 5-digit postal & \\
\hline \multirow[t]{2}{*}{ First New Nearby Laneway House } & $-0.066^{* * *}$ & $-0.047^{*}$ & $-0.036^{* * *}$ & $-0.027 * *$ \\
\hline & $(0.020)$ & $(0.026)$ & $(0.012)$ & $(0.011)$ \\
\hline \multirow[t]{2}{*}{ Postal code got a laneway at some point } & $0.029^{* *}$ & & 0.016 & \\
\hline & $(0.013)$ & & $(0.014)$ & \\
\hline Observations & 10,740 & 2,592 & 10,621 & 5,986 \\
\hline R-squared & 0.723 & 0.648 & 0.736 & 0.695 \\
\hline neighbourhood/time effects + controls & Yes & Yes & Yes & Yes \\
\hline
\end{tabular}

Robust standard errors in parentheses

*** $\mathrm{p}<0.01,{ }^{* *} \mathrm{p}<0.05,{ }^{*} \mathrm{p}<0.1$

Table 6

Effect of a newly built nearby laneway home. This table reports the impact of a property getting a nearby laneway home in the previous year. "Nearby" is defined as a laneway home in the same full 6-digit postal code (Columns 1 and 2) or the 5-digit postal code (Columns 3 and 4 ). Columns 1 and 3 present the results for all data, while Columns 2 and 4 restrict the sample only to properties that eventually got a neighbouring laneway home. 
The estimated coefficients presented in Table ?? show clear negative externalities from the arrival of laneway homes to a postal area. Regression (1) indicates that transacting after the first laneway home is introduced to a block face is associated with a $6.6 \%$ lower price than a transaction in postal code where no laneway home has yet or ever will be constructed. A narrower test that confines the analysis to the subsequent year to arrival only in regression (2) yields a difference equal to $-4.7 \%$. Consistent with more muted effects of new density further away, columns (3) and (4) show impacts for areas defined by the first five characters of the postal code. That effect is $-3.6 \%$ including subsequent year transactions and $-2.7 \%$ for the immediate year following the arrival only.

\subsection{Testing for Randomness in Laneway Home "Assignment"}

Our regression analysis of the own lot and external of laneway construction hinges on the identifying assumption that laneway homes are constructed at random among all newly built eligible houses, contingent on controls. If laneway houses are systematically built in a way associated with unobserved features that affect the price of neighbouring homes, then the estimated coefficients on own or neighbouring laneway house may be biased. Our first test, described above in Section ??, finds that within neighbourhoods, there is little price variation explained by more disaggregated census tracts fixed effects that might be associated with laneway placement.

Our second test evaluates whether houses that get adjacent new-builds with a laneway home differ from those that do not. We take the sample of properties with new neighbours 2012-2017 that also transacted between 2005 and 2008. We estimate their transaction prices in the earlier period, but include as a dummy variable whether they will have a new-build with a laneway home in the postpolicy 2012-2017 period: their price prior to the announcement of the laneway policy as a function of the ex-post realization of their new-build neighbour having 
a laneway home or not. The results of these regressions are shown below in Table ??. Globally, properties that will in the future have a newly built neighbour with a laneway home do not have transaction prices prior to the announcement of the laneway policy that are systematically different from those whose future newbuild neighbours will not have a laneway house. Unlike once laneways are built in 2012-2017, there is no evidence of the pattern by own predicted price that we will find in subsequent tables. In locally-weighted regressions, with weights inversely proportional to deviations of predicted transaction price from quantiles of the price distribution, the estimated coefficients with weights inverse to deviations from 10th and 90th percentiles (specifications (4) and (8)) are essentially identical. The point estimates, though none are statistically different from zero, are for the most part greater than zero, which would suggest that any bias would be towards finding a positive rather than negative effect of laneway homes. 


\begin{tabular}{lccccccccc}
\hline & $(1)$ & $(2)$ & $(3)$ & $(4)$ & $(5)$ & $(6)$ & $(7)$ & $(8)$ \\
VARIABLES & Full Sample & High PP & Very high PP & w10 & w25 & w50 & w75 & w90 \\
\hline \multirow{2}{*}{ Future new neighbor has laneway } & 0.019 & 0.004 & 0.117 & 0.036 & $0.045^{*}$ & $0.042^{*}$ & 0.005 & 0.032 \\
& $(0.030)$ & $(0.077)$ & $(0.177)$ & $(0.025)$ & $(0.024)$ & $(0.021)$ & $(0.023)$ & $(0.027)$ \\
& & & & & & & & & \\
Observations & 983 & 492 & 248 & 983 & 983 & 983 & 983 & 983 \\
$\begin{array}{l}\text { R-squared } \\
\text { neighbourhood/time effects }\end{array}$ & 0.796 & 0.762 & 0.847 & 0.807 & 0.711 & 0.692 & 0.782 & 0.876 \\
\hline
\end{tabular}

Robust standard errors in parentheses

*** $\mathrm{p}<0.01, * * \mathrm{p}<0.05, * \mathrm{p}<0.1$

\section{Table 7}

Random assignment test. The table reports the effect of having a future new-build neighbour with a laneway home versus without on the price of a property prior to the rezoning that allowed laneway homes. Regressions include all lot and property characteristics plus neighbourhood and time effects. Models "High pp" and "Very high pp" are based on sub-samples of properties whose predicted price is above the median and above the 75th percentile. Properties that will get a laneway home post 2009 do not have lower transaction prices 2005-2008 than those that will not among properties that will have new-build neighbour post 2009 . 
Our next robustness test is a broader test of whether new-builds with laneway homes occur in better or worse neighbourhoods than new-builds without. To do so we measure the time $t>T=$ Dec. 2009 share of new homes with laneway homes among all new homes $S_{J}$ where the level of geography $J$ is for census tract or alpha-numeric postal code groups. We then include this share of laneway houses variable in a standard hedonic regression on all transactions prior to 2009 with the same set of controls. The results in Table ?? show no statistically different from zero effect of future sub-neighbourhood area share of new-builds with laneway homes on earlier period prices. We take this as some reassurance that locations with new-builds with laneway homes do not differ from those areas with newbuilds without laneway homes in a manner not captured by our location and unit characteristics controls. 


\begin{tabular}{|c|c|c|c|c|c|c|}
\hline & (1) & $(2)$ & (3) & $(4)$ & $(5)$ & (6) \\
\hline VARIABLES & Tract & Tract & 5-digit code & 5-digit code & $\begin{array}{c}\text { 5-digit code } \\
\text { High PP }\end{array}$ & $\begin{array}{l}\text { 5-digit code } \\
\text { Very high PP }\end{array}$ \\
\hline Share of new w laneway out of all new, CT & $\begin{array}{l}-0.022 \\
(0.063)\end{array}$ & $\begin{array}{c}0.037 \\
(0.056)\end{array}$ & & & & \\
\hline Share of new w laneway out of all new, PC & & & $\begin{array}{c}0.031 \\
(0.034)\end{array}$ & $\begin{array}{c}0.016 \\
(0.020)\end{array}$ & $\begin{array}{c}0.033 \\
(0.033)\end{array}$ & $\begin{array}{l}-0.003 \\
(0.048)\end{array}$ \\
\hline Observations & 8,658 & 8,602 & 8,628 & 8,574 & 4,449 & 2,190 \\
\hline R-squared & 0.498 & 0.611 & 0.499 & 0.612 & 0.476 & 0.327 \\
\hline neighbourhood/time effects & Yes & & Yes & & & \\
\hline neighbourhood/time effects + controls & & Yes & & Yes & Yes & Yes \\
\hline
\end{tabular}

*** $\mathrm{p}<0.01, * * \mathrm{p}<0.05, * \mathrm{p}<0.1$

\section{Table 8}

Random assignment test. This table verifies the random assignment of laneway houses among all newly built properties. We first compute the share of new houses with laneway homes out of all new houses built in the 2012 - 2017 period by census tract and by 5 -digit postal code. We then include these shares in hedonic regressions for all single-family transactions prior to 2010. If laneway homes are systematically built on superior or inferior properties, the share of laneway houses would have a significant impact on pre-2010 transaction prices. Instead, the share of new houses with laneway homes out of all post 2010 new houses has no explanatory power in any of the model specifications we consider. We interpret this result as evidence that laneway houses are randomly assigned among all new houses. All samples presented in this table are limited to properties that are eligible to construct a laneway home. 
Our final random assignment test is whether the specification in Table ?? yields different results over the distribution of house prices. We run the regressions for the five character postal code grouping with the weightings relative to house percentile used above (inverse of distance between an observation's predicted price and the designated predicted house price percentile). These are presented in Appendix Table ??. At the lowest end of the distribution house prices are higher where the new-build with a laneway home share is larger, but this does not hold and appears random for the 25th-90th percentiles. This differs from the consistent increasing negative laneway spillovers as the target percentile increases.

\section{$5 \quad$ Laneway Homes and Welfare}

To approximate the welfare effects of the laneway policy, we consider producer surplus for property owners who exercise the option to add a laneway home, consumer surplus to renters from increased rental supply and variety, and external impacts on nearby residents. We ignore pecuniary effects on rents and prices in other markets due to the new existence of the laneway market.

When the policy came into effect in 2009 for most neighbourhoods and 2013 for others, the market might have absorbed the expected discounted producer surplus and adverse external effects into single family home prices. We are unable to distinguish statistically among a large negative, large positive, or zero net effect. However, we are able to detect the marginal external effect when a new home's owner decides to add a laneway versus not and we also estimate the own-lot effect of that choice. We can thus approximate the effect on owners of an incremental laneway home.

We have estimated average own and external lot effects above. As a large fraction 
of laneway homes are built as part of new-builds, and we believe these effects are more cleanly estimated, we use these coefficient estimates for the welfare estimates developed here. The external welfare effects can be approximated as the average effect per home as captured in the regressions times the number of homes affected. For immediate neighbours, we estimate an average external effect of $-3.8 \%$ per neighbour in Table ??. Summing across immediate neighbours, one front-facing, one rear-facing, one to the right, and one to the left, using the point estimates for behind and across from Appendix Table ??, suggests an average spillover of approximately $-2.2 \% \times 4 \approx-10 \%$ of one single home value for the closest neighbours. For the remaining 7 properties within $50 \mathrm{~m}$ and 29 from 50 $100 \mathrm{~m}$ using point estimates from Table ?? adds $-.006 \times 7-.004 \times 29 \approx-16 \%$ for a total estimated aggregate spillover of $-26 \%$ of one property value. This large magnitude comes with the caveats that most of the effect comes from high value homes, that subsequent laneway homes after the first appear to have smaller impacts, per Table ??, and that standard errors around point estimates are large.

To approximate the benefits of laneway construction on the owners or builders who supply and the renters who demand them, we must distinguish between the market valuation and the willingness to pay among infra-marginal market participants. Appendix Section ?? provides a way to use point estimates for average market prices for laneway homes to infer welfare benefits on the supply side (builders and owners who choose to add laneway homes to their own custom new-builds). There, we approximate the average distance between market price and costs net of financial benefits among inframarginal suppliers. That approach suggests relatively modest net benefits of 2 to $3 \%$ of property value.

For renters, the new availability of small, detached rental homes in single-family neighbourhoods may have created significant surplus. Assuming an approximately linear demand curve around the quantity increase induced by the laneway policy, 
and taking all laneway units as a net increase in aggregate supply (not unreasonable in a highly regulated supply constrained city), the reduction in rents from the increase in quantity would yield a surplus roughly halfway between willingness to pay for similar units absent the laneway policy and rents given the laneway policy. Assuming an average elasticity of -1 for willingness to pay with respect to rental home quantity, ${ }^{30}$ a representative renters' surplus as a fraction of a laneway homes (gross) rental cost would be roughly one-half of the percentage increase in market quantity.

Renters' welfare gain depends on the percentage change in aggregate rental supply from laneway homes and the capitalization of this willingness to pay into an asset value. Approximately 4,000 laneway homes have been built through 2019 in the decade since the laneway program was initiated. By comparison, there were 6,395 single detached homes that are renter occupied and 150,750 total renter occupied units in the City of Vancouver, and 348,000 in Greater Vancouver. ${ }^{31}$ Depending on whether the relevant market is detached rental homes in the City of Vancouver, all rental units in the City of Vancouver, or all rental units in Greater Vancouver, laneway homes have increased market supply by $2 / 3$, or roughly $2.5 \%$, or by just over 1\%. ${ }^{32}$ Taking the intermediate case of a $2.5 \%$ increase in market supply, a representative laneway renter would have a willingness to pay roughly $1 \%$ greater than the cost of their rent. To convert the willingness to pay to an asset value would require the laneway home operating expense ratio and cap rate which we lack. As a simplification we will assume that a laneway home's rental flow as a contribution to value matches its share of a unit's built area. New-builds with a

\footnotetext{
30 The inverse demand elasticity on the intensive margin appears lower (?, but the combined migration and household effects on the intensive margin may be larger).

${ }^{31}$ Metro Vancouver Housing and Data Book (2019), http://www.metrovancouver.org/ services/regional-planning/data-statistics/housing-data-book/Pages/default.aspx.

${ }^{32}$ In each case, those raw percentages assume no reduction in other supply due to diminished rents.
} 
laneway home are 2,023 above grade on average and mean laneway home size is 630 sq ft. This suggests the renter welfare gain from a laneway home is approximately equal to $1 \% \times \frac{630}{2,023+630} \approx 0.25 \%$ of a mean property value.

The estimates calculated above yield a large aggregate negative effect of $-26 \%$ $+2.5 \%+.25 \% \approx-23 \%$ per laneway. The large negative is driven by the large spillovers within a $100 \mathrm{~m}$ radius. If our point estimates are approximately correct, rationalizing the laneway policy on welfare grounds would require a social welfare function that places far greater weight on renters's utility and almost no weight on the negative externality for owner-occupiers. Several recent policy choices by the city are consistent with that weighting. ${ }^{33}$.

\section{Conclusion}

We explore the impact of exercising the right to build a laneway home on one's own property and one's immediate neighbour's property values. Consistent with builder optimization conditions, adding a laneway home adds value to a new property on average in an amount approximately equal to reasonable incremental building costs. However, the positive benefit is smaller and may be below costs for higher priced properties and neighbourhoods, where laneway homes are less frequently found. The value of a laneway home to a buyer in percentage terms declines with property value.

We view our primary contribution as the estimate of the externality associated with increased density, which in our case of ADUs we believe primarily reflects the loss of private property benefit. We measure this through the effect of the presence of a laneway unit on the value of neighbouring houses. Across all properties an

\footnotetext{
$\overline{33}$ For example, the city commonly forgoes up to $\$ 80,000$ per unit in rezoning fees if developers use additional density allowances to build rental, rather than condominium apartments.
} 
adjacent or nearby laneway home has a negative effect on a property's value. This negative effect is strongest for higher priced properties and zero for properties below the median. This pattern is consistent across all our tests.

The pattern in the externality, near zero for lower-priced properties and large and significant for higher-priced properties suggests a much higher willingness to pay for privacy, absence of neighbourhood congestion, or the absence of residents of a different socio-economic class (renters) among wealthier households. The policy implications of our results depend on welfare weighting by income and tenure, though with equal weighting they are negative.

The negative spillovers we find contrast with ?, a study that does not find significant negative spillover effects of density. One explanation for the difference would be that the negative effects we find are concentrated at the high end of the property value distribution (as in ?), and Vancouver's value distribution overall dominates that of most U.S. communities. A second reason for our result may be that we explicitly measure the effects of added neighbourhood density, while ? obtain their identification of external effects from differences in prices, lot coverage, and regulations across two sides of a municipal border.

The addition to the rental stock and the broadening of the location and unit type choices for renters is an unambiguous positive effect on renters' welfare, a clear concern for many affordability-challenged cities. The pattern of our results suggests that laneway homes in neighbourhoods where houses are below the median value does not impose negative externalities. The cost imposed on nearby homeowners increases and the direct benefit to a property owner with added rental density declines as the value of a property increases, so up to some quality level there appear to be Pareto gains to allowing these ADUs. However, the tradeoff between the negative externalities of density and the value of increased housing supply, and hence the best form of any permitted redevelopment, might best be 
evaluated at the neighbourhood level, rather than with city-wide policies. 


\section{Appendix}

\subsection{Laneway Home Guidelines}

Details on rules and regulations can be found at http://vancouver.ca/home-propertydevelopment/building-your-laneway house.aspx. We summarize the more detailed city guiidelines below as follows:

(1) The property needs to back on a lane or another street. Properties that have no lane or street separating them from the property behind are not eligible to build a laneway house. This restriction applies even for corner lots, which in theory have the necessary access for fire and other services. For this reason, we identify all properties for which the lot polygon border is not within 4 meters of a laneway as ineligible.

(2) The requirements for site coverage and access imply that properties with either of these characteristics are not eligible for a laneway house:

- Lot is less than $110 \mathrm{ft}$ deep or narrower than $25 \mathrm{ft}$

- Lot is both less than $33 \mathrm{ft}$ wide and less than $122 \mathrm{ft}$ deep

(3) The total site coverage of the main house and the laneway house cannot exceed $40 \%$ of the property area. This restriction is particularly binding for properties known as "Vancouver Special" because of their size and location within the lot. To identify these properties, we apply the following filters:

- Property built between 1963 and 1986, and

- One story with full basement, and

- Floor area exceeds 1500 sq. ft., and

- Floor area to lot size greater than .5, and

- Lot size is less than 9000 sq. ft.,

- But allow laneway homes for large lots which exceed 148 x 36 feet.

The above criteria for selecting properties eligible for laneway homes appears to 
be accurate. All laneway homes observed in our data are located on properties that satisfy the above criteria. There are no laneway homes on properties that our mechanism labels as ineligible. However, it is conceivable that properties labeled as eligible in our analysis are in fact not eligible. This could potentially bias down any impact of own laneway home eligibility that we find. As well, applicants may appeal to the Director of Planning for a variance.

\subsection{Additional Figures and Tables}




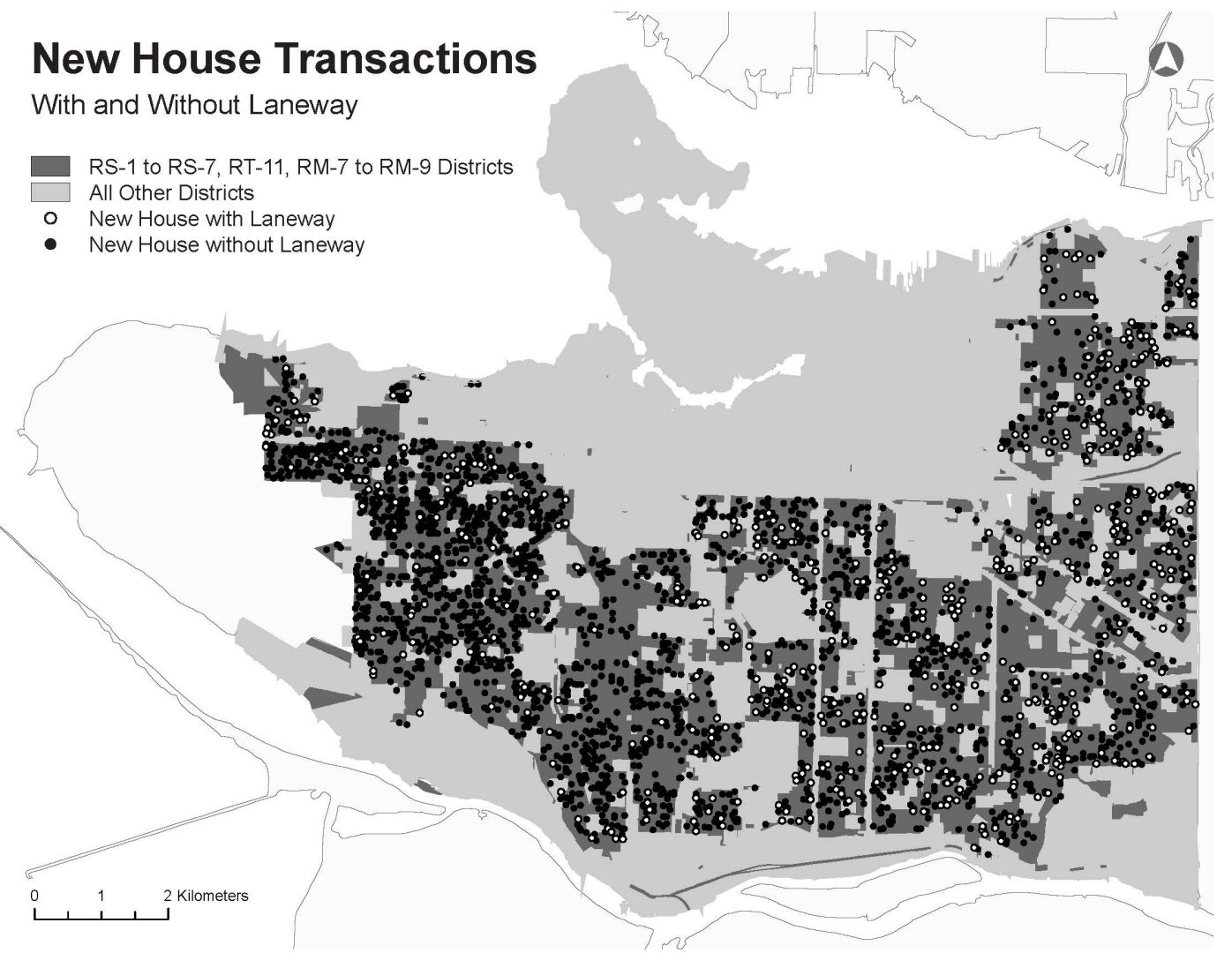

Fig. 2. Location of all new-build transactions. 


\section{Existing Transactions}

With and Without Laneway

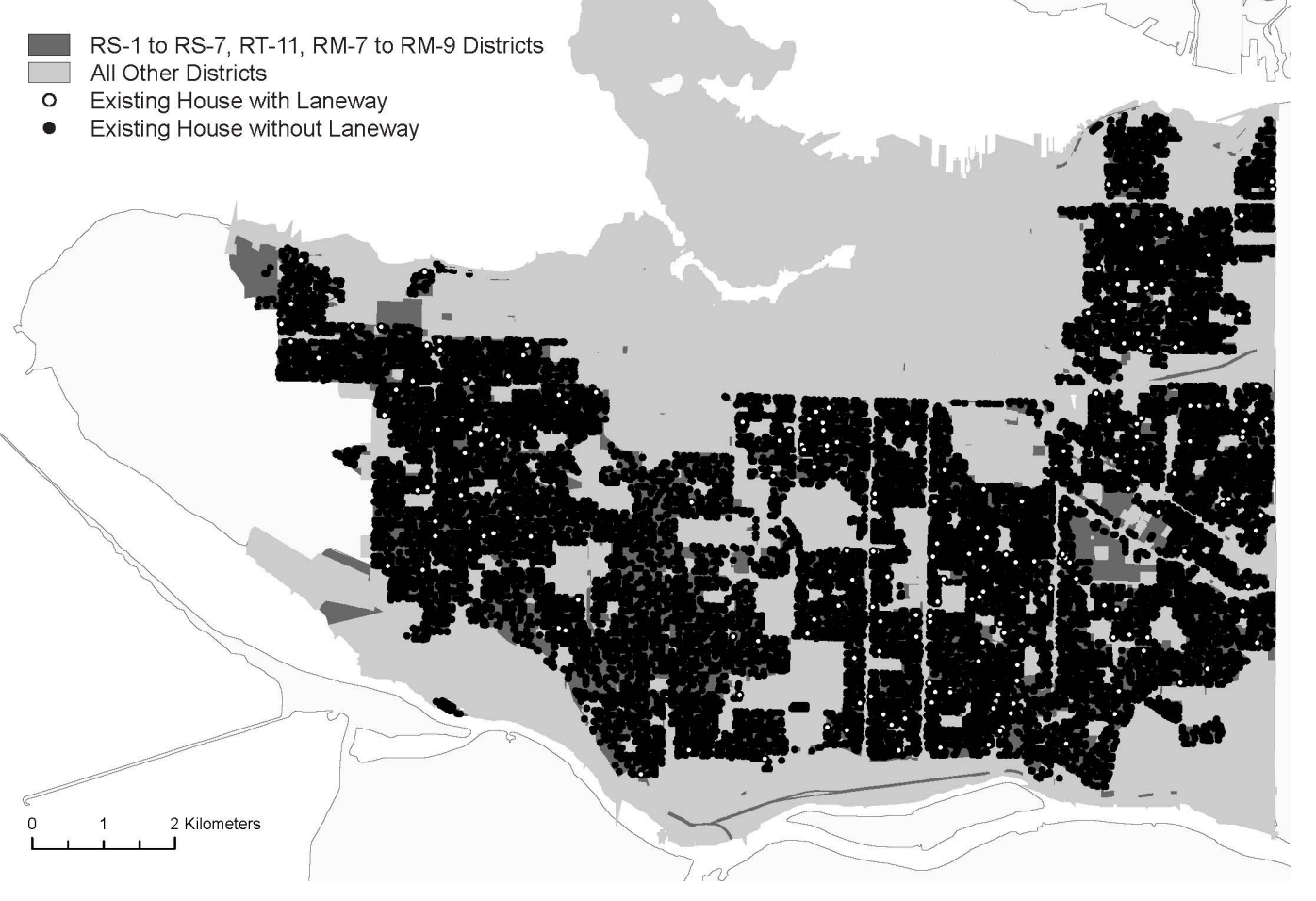

Fig. 3. Location of all existing build transactions. 
New-built neighbour with a laneway

\begin{tabular}{|c|c|c|c|c|c|}
\hline & (1) & $(2)$ & $(3)$ & $(4)$ & (5) \\
\hline VARIABLES & $\mathrm{N}$ & mean & sd & $\min$ & $\max$ \\
\hline price & 535 & $1,633,790$ & 943,269 & 195,250 & $5,500,000$ \\
\hline Finished area 000sf & 535 & 1.615 & 0.606 & 0.600 & 4.041 \\
\hline Lot size 000sf & 535 & 4.831 & 1.616 & 2.750 & 27.080 \\
\hline Age - renovation adjusted & 535 & 28.277 & 22.741 & 0 & 90 \\
\hline Property has a Laneway unit & 535 & 0.155 & 0.362 & 0 & 1 \\
\hline West-side & 535 & 0.327 & 0.470 & 0 & 1 \\
\hline No of laneways within $100 \mathrm{~m}$, excl. own & 535 & 2.583 & 1.627 & 0 & 9 \\
\hline No of 1 -fam within $100 \mathrm{~m}$ & 535 & 42.798 & 10.937 & 8 & 67 \\
\hline No of all resid units within $100 \mathrm{~m}$ & 535 & 47.228 & 15.607 & 8 & 140 \\
\hline \multicolumn{6}{|c|}{ New-built neighbour without a laneway } \\
\hline & (1) & $(2)$ & (3) & (4) & $(5)$ \\
\hline VARIABLES & $\mathrm{N}$ & mean & sd & $\min$ & $\max$ \\
\hline price & 1,709 & $2,198,890$ & 1,355233 & 124,000 & $9,790,476$ \\
\hline Finished area 000sf & 1,709 & 1.909 & 0.736 & 0.654 & 6.209 \\
\hline Lot size $000 \mathrm{sf}$ & 1,709 & 5.215 & 1.812 & 2.011 & 23.960 \\
\hline Age - renovation adjusted & 1,709 & 23.782 & 21.240 & 0 & 102 \\
\hline Property has a Laneway unit & 1,709 & 0.040 & 0.196 & 0 & 1 \\
\hline West-side & 1,709 & 0.641 & 0.480 & 0 & 1 \\
\hline No of laneways within $100 \mathrm{~m}$, excl. own & 1,709 & 0.846 & 1.140 & 0 & 8 \\
\hline No of 1 -fam within $100 \mathrm{~m}$ & 1,709 & 41.163 & 11.290 & 9 & 69 \\
\hline No of all resid units within $100 \mathrm{~m}$ & 1,709 & 44.848 & 18.903 & 13 & 469 \\
\hline
\end{tabular}

Table 9

Summary statistics The table reports the summary statistics for transactions with a newly built neighbour with and without a laneway. 


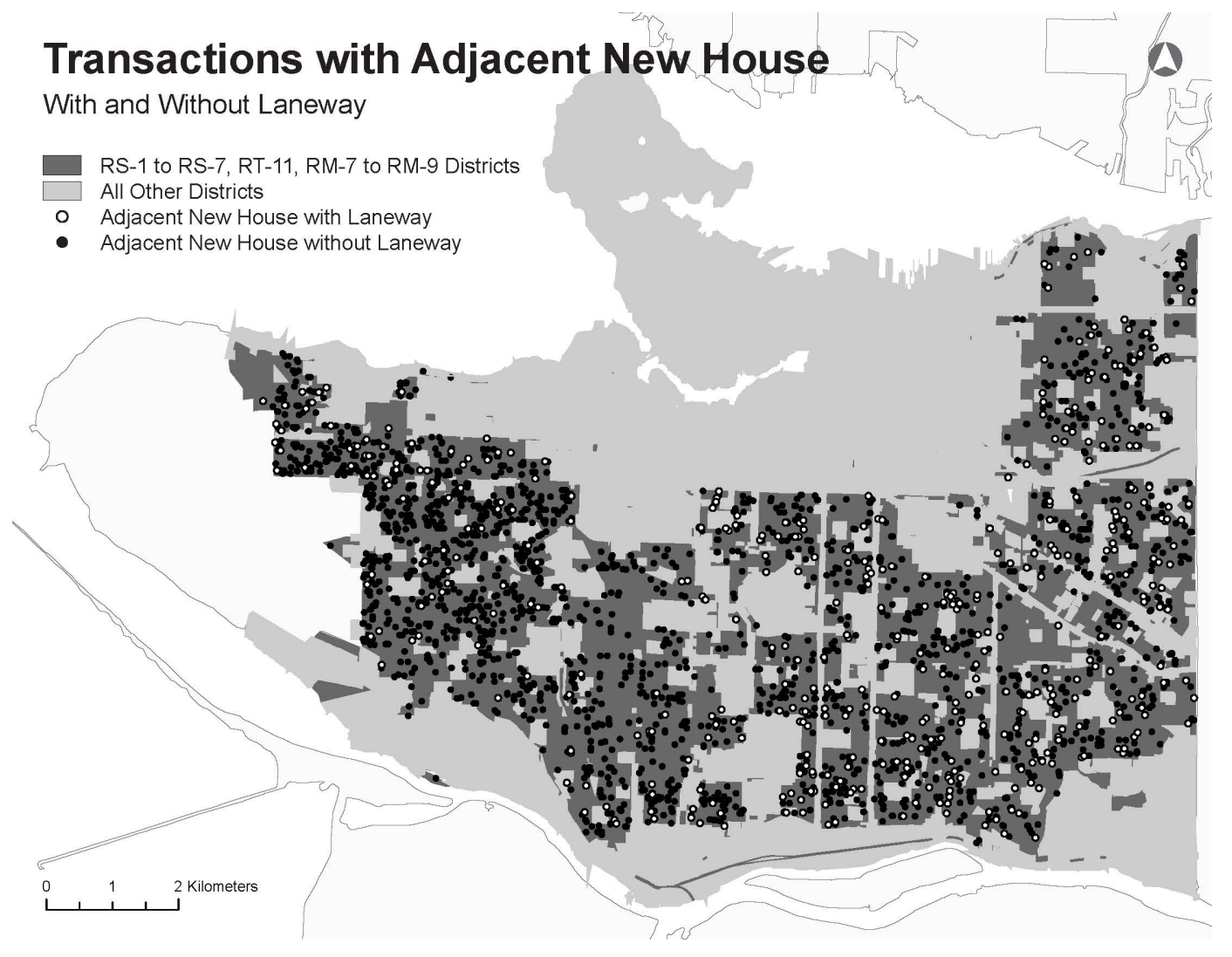

Fig. 4. Location of transactions that are adjacent to a new house.

8 Difference-in-differences estimation of the laneway home policy introduction on property values

The allowance of laneway homes in most RS zones in 2009, and the remainder in 2013, provided homeowners with the option to build a laneway home but also faced property owners with the prospect of future neighbouring laneway homes. To identify the net effect on value, we compare properties that are laneway-eligible based on lot size and existing structure inside the rezoned areas to similar lots outside the rezoned areas. For the 2009 policy introduction, we thus treat lanewayeligible properties that were rezoned in 2009 ("lanewayAllow1"=1) and assign zero treatment (lanewayAllow1=0) to those where laneways were not allowed until 2013 (under the assumption that the subsequently rezoned property owners did 
not anticipate the subsequent change). For the 2013 expansion of the laneway policy, lanewayAllow2 is equal to 1 only in the newly rezoned areas, and is zero in the originally rezoned areas. We consider windows of 6 months or 12 months before and after the policy in which the "post" variable is turned on or off.

The post times treatment coefficients may be interpreted as the effect of being included in the laneway rezoning, which should pick up the net effects of the option plus anticipated externalities. The results are reported in Table ??. We cannot reject any of zero net effect, large negative net effects, or large positive net effects as standard errors are large. The point estimates suggest a negative and not statistically significant effect of $1 \%$ to $3 \%$ around the 2009 change, but a value increase of $4 \%$ to $6 \%$ around the 2013 change. All point estimates are close to or below the insignificant 5\% effect of a 2007 placebo test. We thus have little confidence concerning the magnitude or sign of the option effect, and would be skeptical of the interpretation of statistically interesting results. ${ }^{34}$

\footnotetext{
$\overline{34}$ The difference in lot characteristics that prevent a property from having a laneway means that they are fundamentally different from those properties that can, raising concerns that the random assignment assumption in difference-in-differences estimation is violated. We are also skeptical that buyers and sellers had enough information concerning construction costs to form expectations on the gains to their own potential laneway home or the probability that neighbours would add laneway homes at different points in time.
} 


\begin{tabular}{|c|c|c|c|c|c|c|}
\hline VARIABLES & $\begin{array}{c}(1) \\
2007 \text { falsification } \\
+/-6 \mathrm{mos}\end{array}$ & $\begin{array}{c}(2) \\
2007 \text { falsification } \\
+/-12 \mathrm{mos}\end{array}$ & $\begin{array}{c}(3) \\
2009 \text { rezoning } \\
+/-6 \text { mos }\end{array}$ & $\begin{array}{c}(4) \\
2009 \text { rezoning } \\
+/-12 \mathrm{mos} \\
\end{array}$ & $\begin{array}{c}(5) \\
2013 \text { rezoning } \\
+/-6 \text { mos } \\
\end{array}$ & $\begin{array}{c}(6) \\
2013 \text { rezoning } \\
+/-12 \text { mos } \\
\end{array}$ \\
\hline 1.postJuly 2007 X 1.laneok1 & $\begin{array}{l}0.055 \\
(0.81)\end{array}$ & $\begin{array}{l}0.056 \\
(1.16)\end{array}$ & & & & \\
\hline 1.postJuly2009 X 1.laneok1 & & & $\begin{array}{l}-0.013 \\
(-0.12)\end{array}$ & $\begin{array}{l}-0.035 \\
(-0.98)\end{array}$ & & \\
\hline 1.postJuly2013 X 1.laneok2 & & & & & $\begin{array}{l}0.040 \\
(0.67)\end{array}$ & $\begin{array}{l}0.057 \\
(1.05)\end{array}$ \\
\hline Observations & 2,978 & 4,548 & 2,710 & 4,799 & 1,370 & 2,665 \\
\hline R-squared & 0.545 & 0.530 & 0.593 & 0.571 & 0.653 & 0.648 \\
\hline Neighborhood/time effects + controls & Yes & Yes & Yes & Yes & Yes & Yes \\
\hline
\end{tabular}

Table 10

The table reports effects of the 2008 and 2013 announcements of the granting of the laneway option. The coefficient on the $\mathrm{n}$ term post-July $2008 \mathrm{X}$ laneAllow1 and post-July $2013 \mathrm{X}$ laneAllow2 report the announcement effect on properties with zoning that allowed laneway houses as of July, 2008 and July, 2013, respectively, compared to those that did not. The interaction term is positive and significant at $+/-6$ months of the 2008 announcement, but becomes smaller and not significant for longer estimation windows. The 2013 announcement had no detectable impact on prices. 
All laneway homes and 1-family counts, 100-meter ring

\begin{tabular}{|c|c|c|c|c|c|c|c|c|c|}
\hline & $(1)$ & $(2)$ & $(3)$ & $(4)$ & $(5)$ & $(6)$ & $(7)$ & $(8)$ & $(9)$ \\
\hline VARIABLES & UQ .1 & $\mathrm{UQ} .2$ & UQ .3 & $\mathrm{UQ} .4$ & UQ .5 & UQ .6 & UQ .7 & UQ .8 & UQ .9 \\
\hline No of laneways within $100 \mathrm{~m}$, excl. own & $\begin{array}{c}0.020^{* * *} \\
(0.005)\end{array}$ & $\begin{array}{c}0.027^{* * *} \\
(0.004)\end{array}$ & $\begin{array}{c}0.039^{* * *} \\
(0.004)\end{array}$ & $\begin{array}{c}0.039^{* * *} \\
(0.004)\end{array}$ & $\begin{array}{c}0.027^{* * *} \\
(0.004)\end{array}$ & $\begin{array}{l}-0.003 \\
(0.004)\end{array}$ & $\begin{array}{c}-0.040^{* * *} \\
(0.004)\end{array}$ & $\begin{array}{c}-0.061^{* * *} \\
(0.004)\end{array}$ & $\begin{array}{c}-0.074^{* * *} \\
(0.005)\end{array}$ \\
\hline No of new 1-fam within $100 \mathrm{~m}$ & $\begin{array}{l}-0.005 \\
(0.003)\end{array}$ & $\begin{array}{c}-0.008^{* * *} \\
(0.002)\end{array}$ & $\begin{array}{c}-0.005^{* *} \\
(0.002)\end{array}$ & $\begin{array}{l}-0.003 \\
(0.002)\end{array}$ & $\begin{array}{c}0.004^{* *} \\
(0.002)\end{array}$ & $\begin{array}{c}0.011^{* * *} \\
(0.002)\end{array}$ & $\begin{array}{c}0.014^{* * *} \\
(0.003)\end{array}$ & $\begin{array}{c}0.012^{* * *} \\
(0.003)\end{array}$ & $\begin{array}{c}0.012^{* * *} \\
(0.004)\end{array}$ \\
\hline Property has a Laneway unit & $\begin{array}{l}-0.022 \\
(0.032)\end{array}$ & $\begin{array}{l}-0.009 \\
(0.023)\end{array}$ & $\begin{array}{c}0.011 \\
(0.024)\end{array}$ & $\begin{array}{c}0.068^{* * *} \\
(0.025)\end{array}$ & $\begin{array}{c}0.082^{* * *} \\
(0.023)\end{array}$ & $\begin{array}{c}0.074^{* * *} \\
(0.023)\end{array}$ & $\begin{array}{l}0.055^{*} \\
(0.029)\end{array}$ & $\begin{array}{c}-0.101^{* * *} \\
(0.027)\end{array}$ & $\begin{array}{c}-0.216^{* * *} \\
(0.030)\end{array}$ \\
\hline Observations & 21,175 & 21,175 & 21,175 & 21,175 & 21,175 & 21,175 & 21,175 & 21,175 & 21,175 \\
\hline R-squared & 0.121 & 0.303 & 0.442 & 0.526 & 0.592 & 0.632 & 0.622 & 0.534 & 0.386 \\
\hline neighbourhood/time effects + controls & Yes & Yes & Yes & Yes & Yes & Yes & Yes & Yes & Yes \\
\hline
\end{tabular}

Robust standard errors in parentheses

${ }^{* * *} \mathrm{p}<0.01,{ }^{* *} \mathrm{p}<0.05,{ }^{*} \mathrm{p}<0.1$

\section{Table 11}

Effect of nearby laneway homes. This table reports the estimation of Equation (??) for all transactions using the laneway counts and single-family counts using unconditional quantile regression. The regressions range from the quantile regression on the 10th percentile (regression (1)) to the quantile regressions for 90th percentile (regression (9)). Negative effects of nearby laneway homes only manifest for quantile regressions for the 70th percentile and above. All regressions have controls for property and lot characteristics, neighbourhood-year fixed effects, and city wide year-month fixed effects. 
All laneway homes and 1-family counts, 100-meter ring

\begin{tabular}{|c|c|c|c|}
\hline & (1) & $(2)$ & $(3)$ \\
\hline VARIABLES & Full sample & High pp & Very high pp \\
\hline \multirow[t]{2}{*}{ Only 1 laneway house within $100 \mathrm{~m}$} & $-0.028 * * *$ & $-0.047^{* * *}$ & $-0.045^{* * *}$ \\
\hline & $(0.008)$ & $(0.011)$ & $(0.016)$ \\
\hline \multirow[t]{2}{*}{ Two laneway houses within $100 \mathrm{~m}$} & $-0.037^{* * *}$ & $-0.047^{* * *}$ & $-0.070^{* * *}$ \\
\hline & $(0.010)$ & $(0.013)$ & $(0.018)$ \\
\hline \multirow[t]{2}{*}{ Three or more laneway houses within $100 \mathrm{~m}$} & $-0.029 * *$ & $-0.039 *$ & $-0.048^{*}$ \\
\hline & $(0.014)$ & $(0.023)$ & $(0.026)$ \\
\hline \multirow[t]{2}{*}{ No of new 1-fam within $100 \mathrm{~m}$} & 0.004 & 0.006 & 0.003 \\
\hline & $(0.003)$ & $(0.004)$ & $(0.005)$ \\
\hline Observations & 20,930 & 9,806 & 4,552 \\
\hline R-squared & 0.700 & 0.554 & 0.444 \\
\hline neighbourhood/time effects + controls & Yes & Yes & Yes \\
\hline
\end{tabular}

Robust standard errors in parentheses$$
* * * \mathrm{p}<0.01, * * \mathrm{p}<0.05, * \mathrm{p}<0.1
$$

Table 12

Effect of nearby laneway homes The table reports the estimation of Equation (??) for all transactions using the laneway counts and single-family counts similarly to Table ??, except the counts are included as categorical variables. "High pp" and "Very high pp" are based on sub-samples of properties whose predicted price is above the median and above the 75th percentile, respectively. Overall, it is the first and second laneway homes that are associated with lower property values, but in the sample of higher value homes three or more can also have a statistically different than zero negative effect. Point estimates of the negative externality are higher for the sample restricted to higher-valued properties, based on predicted value. All regressions have controls for total single-family units within the $100 \mathrm{~m}$ ring, property and lot characteristics, neighbourhood-year fixed effects, and city wide year-month fixed effects. 
Single-family neighbourhoods, new neighbours only

\begin{tabular}{|c|c|c|c|c|c|c|c|c|c|}
\hline & $(1)$ & $(2)$ & $(3)$ & $(4)$ & $(5)$ & (6) & (7) & $(8)$ & $(9)$ \\
\hline VARIABLES & UQ .1 & UQ .2 & UQ .3 & UQ .4 & UQ .5 & UQ .6 & UQ .7 & UQ .8 & UQ .9 \\
\hline New neighbour has laneway & $\begin{array}{c}0.166^{* *} \\
(0.084)\end{array}$ & $\begin{array}{c}0.067 \\
(0.064)\end{array}$ & $\begin{array}{l}-0.026 \\
(0.053)\end{array}$ & $\begin{array}{c}0.052 \\
(0.047)\end{array}$ & $\begin{array}{l}-0.024 \\
(0.043)\end{array}$ & $\begin{array}{l}-0.009 \\
(0.038)\end{array}$ & $\begin{array}{l}-0.061 \\
(0.038)\end{array}$ & $\begin{array}{c}-0.096^{* *} \\
(0.043)\end{array}$ & $\begin{array}{l}-0.050 \\
(0.046)\end{array}$ \\
\hline Observations & 1,312 & 1,312 & 1,312 & 1,312 & 1,312 & 1,312 & 1,312 & 1,312 & 1,312 \\
\hline R-squared & 0.326 & 0.488 & 0.596 & 0.677 & 0.685 & 0.658 & 0.613 & 0.545 & 0.438 \\
\hline neighbourhood/time effects + controls & Yes & Yes & Yes & Yes & Yes & Yes & Yes & Yes & Yes \\
\hline
\end{tabular}

Robust standard errors in parentheses

*** $\mathrm{p}<0.01, * * \mathrm{p}<0.05, * \mathrm{p}<0.1$

Table 13

Effect of immediate neighbour's laneway home (new neighbours only). This table reports unconditional quantile regressions, The regressions range from the quantile regression on the 10th percentile (regression (1)) to the quantile regressions for 90th percentile (regression (9)). Negative effects of nearby laneway homes only manifest for quantile regressions for the 70th percentile and above. All regressions have controls for property and lot characteristics, neighbourhood-year fixed effects, and city wide year-month fixed effects. 
Single-family neighbourhoods, new neighbours only

\begin{tabular}{lcccc}
\multicolumn{5}{c}{ Single-family neighbourhoods, new neighbours only } \\
& $(1)$ & $(2)$ & $(3)$ & $(4)$ \\
VARIABLES & & & All controls & All controls \\
& No controls & Neigh/time effects & neigh & CT \\
\hline New neighbour has laneway & & & & \\
& $-0.315^{* * *}$ & -0.061 & $-0.096^{* * *}$ & $-0.097^{*}$ \\
& $(0.116)$ & $(0.044)$ & $(0.034)$ & $(0.052)$ \\
Observations & & & & \\
R-squared & 1,153 & 1,153 & 1,153 & 1,153 \\
neighbourhood/time effects + controls & No & 0.678 & 0.795 & 0.825 \\
\hline
\end{tabular}

Robust standard errors in parentheses

$* * * \mathrm{p}<0.01, * * \mathrm{p}<0.05, * \mathrm{p}<0.1$

\section{Table 14}

Effect of immediate neighbour's laneway home (new neighbours only). This table repeats the analysis in Table ??, but is confined to census tracts with more than the median (11) number of transactions with adjacent new homes with laneway units. The purpose is to identify the effect of increasing specificity of control variables, in particular the introduction of census tract dummies (column 4). 
New neighbours only, broader definition of a neighbour

\begin{tabular}{|c|c|c|c|c|c|c|}
\hline & (1) & $(2)$ & $(3)$ & $(4)$ & (5) & $(6)$ \\
\hline VARIABLES & Full sample & Full sample & High pp & High pp & Very high pp & Very high pp \\
\hline \multirow[t]{2}{*}{ New neighbour has laneway } & -0.038 & & $-0.057^{*}$ & & $-0.120^{* * *}$ & \\
\hline & $(0.026)$ & & $(0.031)$ & & $(0.043)$ & \\
\hline \multirow[t]{2}{*}{ New nearby house has a laneway } & & -0.022 & & -0.022 & & $-0.086^{* *}$ \\
\hline & & $(0.022)$ & & $(0.023)$ & & $(0.038)$ \\
\hline Observations & 1,312 & 2,270 & 850 & 1,372 & 472 & 776 \\
\hline $\mathrm{R}$-squared & 0.789 & 0.794 & 0.708 & 0.702 & 0.610 & 0.557 \\
\hline neighbourhood/time effects + controls & Yes & Yes & Yes & Yes & Yes & Yes \\
\hline
\end{tabular}

Robust standard errors in parentheses

*** $\mathrm{p}<0.01,{ }^{* *} \mathrm{p}<0.05,{ }^{*} \mathrm{p}<0.1$

Table 15

Effect of new neighbour's laneway home (new neighbours only), broader definition of a neighbour. This table repeats the analysis in Table ?? and also includes the results from a broader definition of a neighbour. Specifically, we include neighbours behind and in front of the house (across the street), in addition to the neighbours to the left and the right. 


\begin{tabular}{llll}
\hline Table & Universe of homes & Log coefficient & Level coefficient (full regression not shown) \\
\hline 3 & New & 0.113 & 180,794 \\
3 & New East & $.155^{* * *}$ & $192,449.665^{* * *}$ \\
3 & New West & 0.037 & 161773.881 \\
5 & All with new neighbour & -0.038 & $-82,605.745^{* *}$ \\
5 & All with new neighbour, w10 & -0.009 & -26815.78 \\
5 & All with new neighbours, w90 & $-0.072^{* * *}$ & $-209,725.772^{* * *}$ \\
\hline
\end{tabular}

Table 16

Comparison of coefficients This table compares the coefficient estimates from measuring the dependent variable in logs and in levels.

\begin{tabular}{lccccc}
\hline & $(1)$ & $(2)$ & $(3)$ & $(4)$ & $(5)$ \\
VARIABLES & w10 & w25 & w50 & w75 & w90 \\
\hline Share of new w laneway out of all new, PC & $0.051^{*}$ & 0.015 & -0.003 & 0.016 & -0.022 \\
& $(0.030)$ & $(0.011)$ & $(0.013)$ & $(0.015)$ & $(0.016)$ \\
& & & & & \\
Observations & 8,574 & 8,574 & 8,574 & 8,574 & 8,574 \\
R-squared & 0.325 & 0.327 & 0.365 & 0.607 & 0.772 \\
neighbourhood/time effects + controls & Yes & Yes & Yes & Yes & Yes \\
\hline
\end{tabular}

Robust standard errors in parentheses

$* * * \mathrm{p}<0.01, * * \mathrm{p}<0.05,{ }^{*} \mathrm{p}<0.1$

\section{Table 17}

Random assignment test. This table verifies the random assignment of laneway houses among all newly built properties in a manner similar to Table ?? except using weighted regression. We first compute the share of new houses with laneway homes out of all new houses built in the 2012 - 2017 period by 5-digit postal code. We then include these shares in hedonic regressions for all single-family transactions prior to 2010. If laneway homes are systematically built on superior or inferior properties, the share of laneway houses would have a significant impact on pre-2010 transaction prices. Instead, the share of new houses with laneway homes out of all post 2010 new houses has no explanatory power in any of the model specifications we consider. We interpret this result as evidence that laneway houses are randomly assigned among all new houses. All samples presented in this table are limited to properties that are eligible to construct a laneway home.

\section{Supply-side benefits of allowing laneway homes}

Let $\beta_{j}$ be the market premium (possibly negative) for a completed home with a laneway relative to an otherwise identical home. $\beta_{j}$ should approximately equal the mean willingness to pay for a laneway (net of lost yard space and privacy). Speculative home builders or homeowners hiring custom builders will presumably 
add laneways if they face a cost of building a laneway less than $\beta_{j}$. For a speculative builder $i$, the cost would be equal to a mean cost of construction (" $\$ k "$ ) plus an idiosyncratic cost term that we label $\epsilon_{i}$. For a homeowner, the term $\epsilon$ might include both their chosen builder's laneway pricing deviation from the mean plus their idiosyncratic distaste for lost yard space (the mean distaste would be incorporated in $\beta_{j}$ ), minus their idiosyncratic valuation of rental income from the laneway and expected future sale revenue difference attributable to the laneway (mean rental valuation and future sales expectations would again be part of $\beta$ ). In principle, the cost $k$ should include the foregone option of building a laneway home later. However, given the economies of scale and modest take-up of laneways to date, we consider it reasonable to neglect that option in $k$.

The mean willingness to pay $\beta$, the mean cost $k$, and the deviation $\epsilon$ are measured in dollars, although we will parameterize the amounts $\beta$ and $\epsilon$ as fractions of neighbourhood mean price of new homes. This characterization allows for possible systematic variation in laneway homes across geography through the neighbourhood mean net valuation $\beta_{j}$.

A homeowner or builder will thus build a laneway home if the net benefit of doing so is positive, that is, if:

$$
\left[\epsilon_{i}+k-\beta_{j}\right]<0
$$

Before parameterizing the distribution of $\epsilon$, a reasonable first question is whether the prevalence of laneways particularly among new-builds in East Vancouver makes sense economically. ? suggests typical annual rent of roughly $\$ 20,000$ per year. Assuming incremental tax and maintenance costs at a relatively high level 
of $\$ 7,500$ per year would leave a net operating income of $\$ 12,500$, a bit over $6 \%$ of typical incremental costs on a new home $k$ of $\$ 200,000 .{ }^{35}$ Apartment cap rates in Vancouver are typically well lower than that, with low rise building cap rates ranging from $3.25 \%$ to $4.25 \%$ per CBRE commercial in 2020. Assuming a $4 \%$ cap rate requirement for homeowners, this would leave $2 \%$ of cost, or roughly $\$ 4,000$ per year, as compensation for lost privacy and garage space. That this would be adequate compensation in relatively more affordable neighbourhoods and insufficient compensation in the more expensive West Side seems quite plausible.

We use the characterization of the owner or builder's benefit from equation ?? as the basis for estimating the own welfare gain from building a laneway home. If the idiosyncratic distaste $\epsilon$ has a distribution with mean zero and variance depending on a parameter $\Theta$, then the expected fraction of new homes that are supplied with a laneway home would be the cumulative distribution $F\left(k-\beta_{J}, \Theta\right) . F$ is a supply function, with $\beta_{j}$ representing price. To compute average producer surplus, we compute the average difference between market price $\beta_{j}$ and net cost $k+\epsilon_{i}$.

Using the c.d.f. $F$, we can approximate welfare gains to owners using the differences in mean valuations and uptake between the city's east and west sides. From Table ??, a laneway home on the West Side of Vancouver is associated with an increase in sale price of roughly 3.7\%. At a mean price of new homes of $\$ 2.66$ million on the West Side, this is just under $\$ 100,000$. A construction cost of $k=\$ 200,000$ would then imply a value for $k-\beta$ of $-\$ 100,000$. This suggests that $\epsilon=\frac{-100,000}{2,660,000} \approx-3.7 \%$ of value would be the maximal $\epsilon$ idiosyncratic net cost at which an owner would purchase. ${ }^{36}$ Approximately $17 \%$ of new homes in the West Side of Vancouver have laneway homes. With $\epsilon$ represent$\overline{35} \$ 200,000$ comes from discussions with builders. This is consistent with ? data which show a median cost to owners between $\$ 200,000$ and $\$ 300,000$, recognizing some markup over costs to end users and the absence of economies of scale among older homes which form a part of the survey.

36 To match the $\$ 100,000$ negative net benefit at the West Side mean. 
ing a fraction of value, and assuming that fraction to be normally distributed, to attain $\Phi(-.037, \mu=0, \sigma)=.17$ would imply $\sigma \approx .04$, so that a one standard deviation increase in net benefits from a laneway home would represent $4 \%$ of value. The inframarginal owners would thus be expected to derive value $U=-\int_{-\infty}^{-.037} x \phi(x, \mu=0, \sigma=.04) d x-3.7 \% \approx 2.2 \%$ of the home as net surplus.

Uptake of laneway homes is higher on the city's East Side, approximately $50 \%$ of new homes have laneway homes, so the estimated benefit differs. Table ?? suggests a mean valuation $\beta_{j}$ of $15.5 \%$ of value for laneway homes. The mean value of a new East Side home is just over $\$ 1$ million in our sample, suggesting a shortfall of approximately $\$ 45,000$ or roughly $4.5 \%$ of value between willingness to pay for laneway homes and construction cost. On the other hand, a regression in levels (unreported in Table ??) finds that laneway homes are associated with an increase of $\$ 191,000$, very close to a plausible value of $k$ and thus quite consistent with approximately 50\% uptake. Assuming breakeven at the population mean of $\epsilon=0$ and the West Side-implied $\sigma$ value of $-4 \%$ implies a truncated expectation $-\int_{-\infty}^{0} x \phi(x, \mu=0, \sigma=.04) d x=3.1 \%$ of value as average surplus from the laneway home among those who purchase new homes with laneway units.

That idiosyncratic preferences of particular owners drives purchases in neighbourhoods where the mean own-price effect does not rationalize the cost is consistent with a finding concerning who builds laneway homes. On the less expensive East Side, roughly $50 \%$ of new homes have laneway units, and that fraction is roughly equal across homes that are sold shortly after construction (likely "spec" homes, where builders hope to profit from construction and sale, versus custom homes built on behalf of an owner and not resold after completion). On the West Side, where the premium to a new home with a laneway unit is less likely to rationalize its placement in a spec build per Table ??, we find that laneway homes are roughly $50 \%$ more prevalent (19\% versus $12 \%$ ) among apparently custom homes 
than spec homes. The very low take-up rates among existing homes indicates that the number of owners willing to pay the incremental cost of construction for existing homes, which may be as high as $\$ 500,000$ is quite small, consistent with our modest approximation of idiosyncratic willingness to pay. ${ }^{37}$

$\overline{{ }^{37} \mathrm{Much}}$ larger valuations could be found by estimating the incremental value of a laneway home among new-builds by neighbourhood, but the standard errors are very large in those estimates, yielding artificially large point estimate magnitudes. 